\title{
Plasma-based Nanotechnology for Textile Coating
}

Hend M. Ahmed and A.A. El-Halwagy

Dyeing, Printing and Auxiliaries Department, Textile Research Division, National Research Centre, Cairo 12622, Egypt.

\begin{abstract}
$\mathbf{T}$ HIS REVIEW presents the significance of nanotechnology as a new tool in textile printing to introduce multifunctional properties. Nanostructures, such as nano-fibers, nano-coatings, nano-finishing and nano-composites, have potentially revolutionized the textile manufacturing industry with high performance characteristics, such as electrically conductivity, self-cleaning, hydrophobicity or hydrophilicity, flame-retardant, antimicrobial properties and ultraviolet protection, as well as improving their printing performance, without changing the bulk properties of the coated fabrics. There are various techniques have been applied to explore the properties of the coated fabric surface, including scanning electron microscopy (SEM), atomic force microscopy (AFM), transmission electron microscopy (TEM), X-ray diffraction analysis (XRD), Fourier-transform infrared spectroscopy (FTIR) and scanning probe microscopy (SPM).
\end{abstract}

\section{Introduction}

Nanotechnology is defined as the generation of practical nano-scaled materials and devices and exploitation of modern phenomenon and Characteristics (physical, chemical and biological at that size scale ${ }^{1,2}$. It has been caught large observation in the textile field and mostly Focused on the application of nanomaterials in the production of structures of nanoparticles during manufacturing, coating and finishing ${ }^{3,}{ }^{4}$.

Recent articles are interested in the development and possible applications of nanotechnology in textile field for improving their multifunctional, nanofibers, smart nanocomposite fibers and new nanofinishing textiles ${ }^{5}$. The application of nanotechnology in textile produced antibacterial properties ${ }^{6}$ self-cleaning, flame resistant, super hydrophobic and insect repellent to prevent disease, electrical conductivity ${ }^{7}$, and Ultraviolet light protection. Microscopy analysis is an important apparatus in nanotechnology, which has been broadly used for the examination of particle dimension, the symmetry of nanocomposite coatings and size distribution. Besides, it can, also, be used to appear the thickness of the applied nanolayer, the properties of the surface, and the 3D morphology of the surfaces. Some of these microscopy analysis are Scanning Microscope SEM, Transmission Electron Microscope TEM,
Atomic Force Microscope AFM and X-Ray Diffraction XRD.

This article review discuss the large wide methods applied for nanocoating process and its application in textile industry such as sol- gels technique, layer-by-layer, plasma polymerization and others 5. These methods acquire the treated textiles different potential properties. Table I, provides an overview of various nanomaterials used and the gained textile potential properties achieved.

Methods for deposition of nanoparticles on textiles fabric

Sol gels technique

In the early 1960s, sol-gel processes appeared and were subsequently development for the requisite new methods for preparing nuclear reactions. This development began to become popular around 1984 and reached its magnificence in $2011^{10}$. In recent years it has become a sol - gel technology of the most important processes in the textile industry due to many reasons; cheaper, less chemicals consumption, more interactive, and giving the characteristics of the new functionality textiles with high durability ${ }^{11}$. Solgel is, also producing a highly purified matter formed like ultra-thin film coating, powders, filaments, and self-confirming of bulk configurations ${ }^{12}$. The process of sol - gel can be described as a network formation of oxides through multiple condensations of the particular precursors in liquid ${ }^{13}$. 
TABLE I. Functions of Nano textiles depended on the Nanomaterial used 8, 9.

\begin{tabular}{ll}
\hline Properties of nanotextiles & \multicolumn{1}{c}{ Nanomaterial } \\
\hline Electro- conductive/antistatic & $\begin{array}{l}\text { Carbon black, Carbon nanotubes (CNT) Copper, } \\
\text { Polypyrrol, Polyaniline }\end{array}$ \\
Increased durability & $\begin{array}{l}\text { Aluminum oxide, CNT, Polybutyl acrylate, Silicon } \\
\text { dioxide, Zinc oxide }\end{array}$ \\
Antimicrobial & $\begin{array}{l}\text { Silver, Chitosan, Silicon dioxide } \\
\text { Titanium dioxide, Zinc oxide }\end{array}$ \\
Celf-cleaning/dirt and water repellent & $\begin{array}{l}\text { CNT, Fluoroacrylate, Silicon dioxide Titanium dioxide } \\
\text { (anatase) }\end{array}$ \\
Moisture-absorbent & $\begin{array}{l}\text { Titanium dioxide } \\
\text { Carbon black, Nanoporous hydrocarbon-nitrogen } \\
\text { Improved dyeability }\end{array}$ \\
coating, Silicon dioxide \\
UV protection, protection from fading & Titanium dioxide (rutile), Zinc oxide \\
Fire resistance & CNT, Boroxosiloxane, Montmorillonite (nanoscale \\
clay), Antimony ash & CNT \\
Abrasion resistance & \\
\hline
\end{tabular}

A sol is an established diffusion of colloidal molecules or polymers in solvent where, molecules could be crystalline or amorphous. The aerosol is molecules in a gas phase, while Sol is molecules in a liquid ${ }^{14}$. A gel is consisting of molecules in the form of the three-dimensional incessant network, which consists of a liquid phase in a colloidal gel. The polymer complex is constructed from the accumulation of colloidal particles. In general, the molecules may interact by the forces of sol van der or hydrogen bonds. ${ }^{14}$.
A colloidal suspension is required to form a network, a compound consisting of a metal or metalloid element such as silicon alkoxides $\left[\mathrm{Si}(\mathrm{OR})_{4}\right]$ which surrounded by various ligands [14]. Where metal oxides contain reactive oxide groups (-OR), which easily react with water in the hydrolysis reaction in the presence of a metal catalyst. where the oxide group changed with the hydroxyl group (-OH), which are produced during the reaction of condensation to form metalloxane linkage $(\mathrm{M}-\mathrm{O}-\mathrm{M})^{15}$.

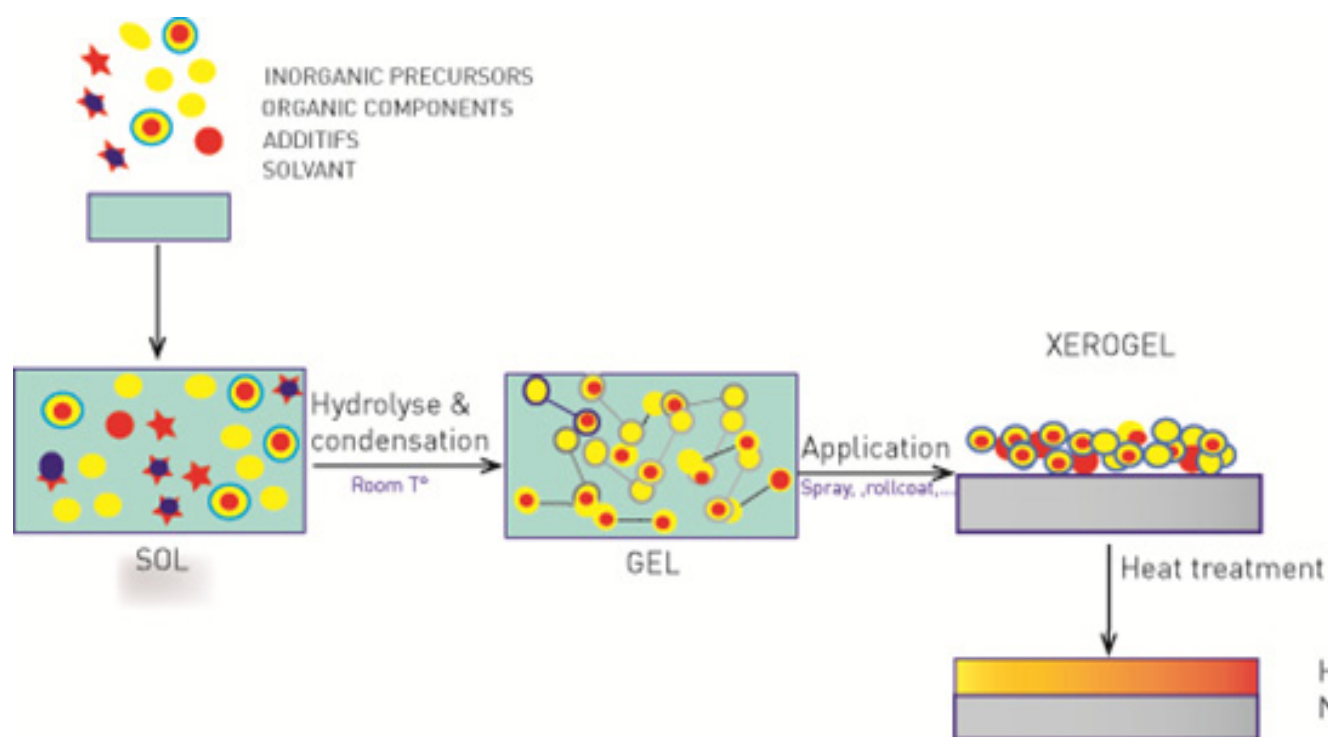

Fig. 1. Sol-gel procedure mechanism. 


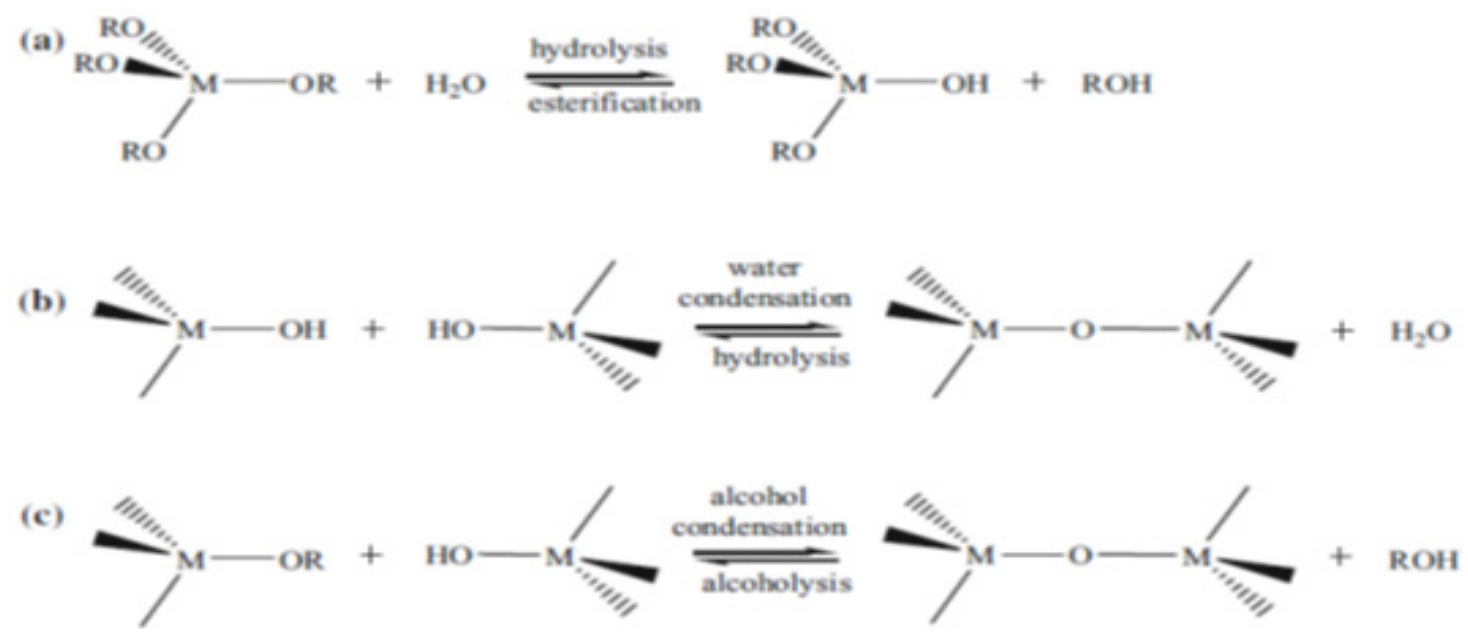

Fig. 2. Hydrolysis (a) and condensation (b, c) of metal alkoxides.

These types of reaction continue to construct a network polymer containing a large number of minerals with a three-dimensional structure through the polymerization process. The complex properties of the gel-liquid solution are attach to some factors that influence the amount of hydrolysis and condensation reactions, such as temperature, reaction time, $\mathrm{pH}$, reagent concentrations, catalyst concentration, aging temperature and time. ${ }^{16}$.

A pad-dry-cure method is considered an application of a sol-gel technique in the biochemical finishing of textile industry, which consists of the immersion of textile fibers in the sol solution and then the fiber is dried and curried under suitable conditions where, during drying and curing process, the nano polymer film is formed on the fiber surface ${ }^{17}$.

Recently, the potential of the process of solgel compounds in the formation of nanoscale materials and the organization of nanoparticles without a breakdown of their structure or function properties have given interesting results in different applications $18 \mathrm{New}$ York\&\#xD; $<$ / publisher $><$ urls $><$ /urls $></$ record $></$ Cite $></$ EndNote $>, 19,20,21,22$. The possible applications of sol-gel in the textile fabric as UV protection, antibacterial activity, flame retardant, self-cleaning... etc. ${ }^{23}$.

To produce an efficient UV protection fabric, it has to include high ultraviolet protection factor (UPF) at 300-320 nm. Fig. 6 clears the procedure of UV protection for treated textile fabrics by nanosol-gel where, the nanosol-gel process does as UV protection by scattering, reflection and absorption, mechanisms ${ }^{24}$.
The cotton fabric treated with the $\mathrm{ZnO}$ nanosol-gel gave good UV blocking whereas after 50 cycles washing-dried. This clears that the solgel coating has excellent adhesion surface of the textile 25,26

Berendjchi et al. ${ }^{27}$, Using silica sol gel loaded with copper $(\mathrm{Cu})$ nanoparticles to manufacture the surface of cotton fabric has antibacterial properties. The decomposition of tetraethyl orthosilicate and condensation in the water to achieve nanoparticles colloidal silica at room temperature. Treatment samples showed excellent anti-bacterial properties due to deposits of copper nanoparticles on nano-silica particles where, the antibacterial properties of nanoparticles of metal has a strong association with their sizes Fig. 4.

Recently, there's growing regard for the utilization of sol-gel nanocomposites as flameretardants due to the characteristic gains of performance and therefore the excellent coating than the normal methods [28]. It provides a simple and suitable way for the synthesis of advanced materials which applying them to get the flameretardants free from halogen. and therefore the study of flame-retardant for poly-Acrylonitrile (PAN) fabric based on the hybrid compound which containing phosphorus acid by using a solgel process [29].

The results showed that, the action of phosphorus include flame retardants is identified as "condensed phase" process [30] where the orthophosphoric acid create from thermal decomposition will produce more residual impurities and fewer flammable by-products and stop the propagation of the fiber Zhang et al. ${ }^{28}$.

J. Text. Color. Polym. Sci. Vol. 18, No. 1 (2021) 


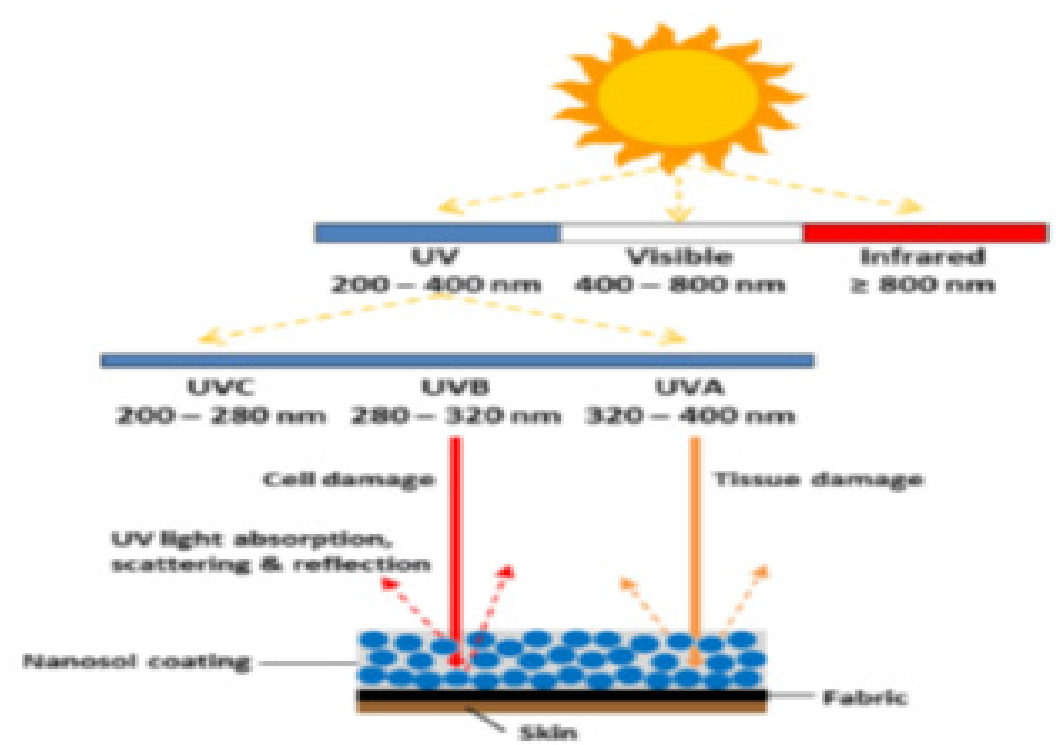

Fig. 3. Ultraviolet protection mechanism of nanosol-treated fabric ${ }^{20}$.

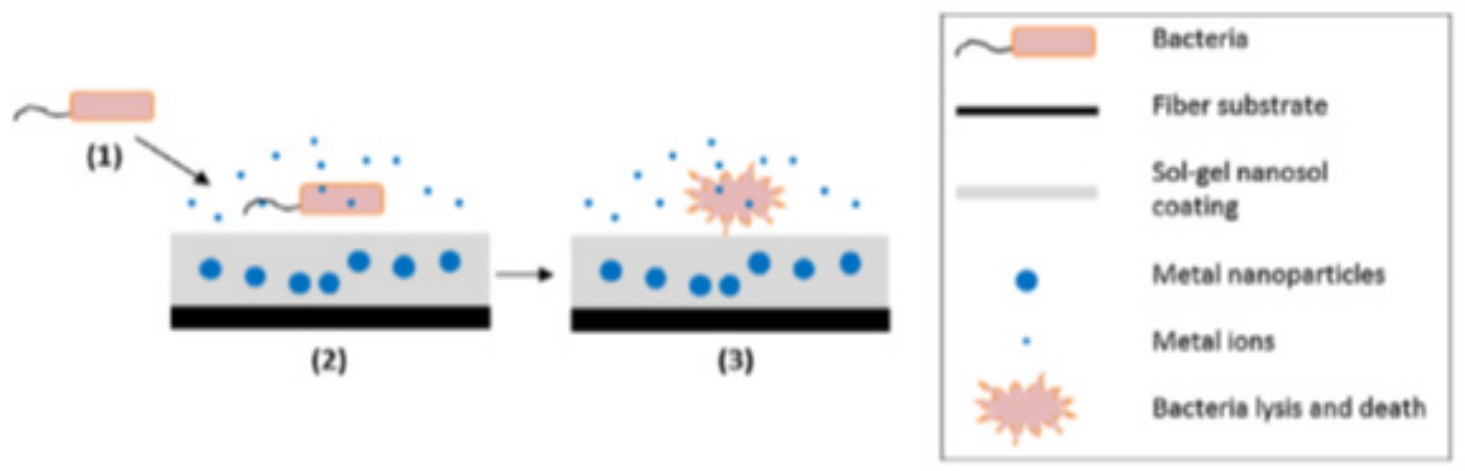

Fig. 4. Antibacterial mechanism of nanosol gel treated fabric where, (1) bacterial attack, (2) bacterial linkage and metal ions deposition, (3) bacterial decease.

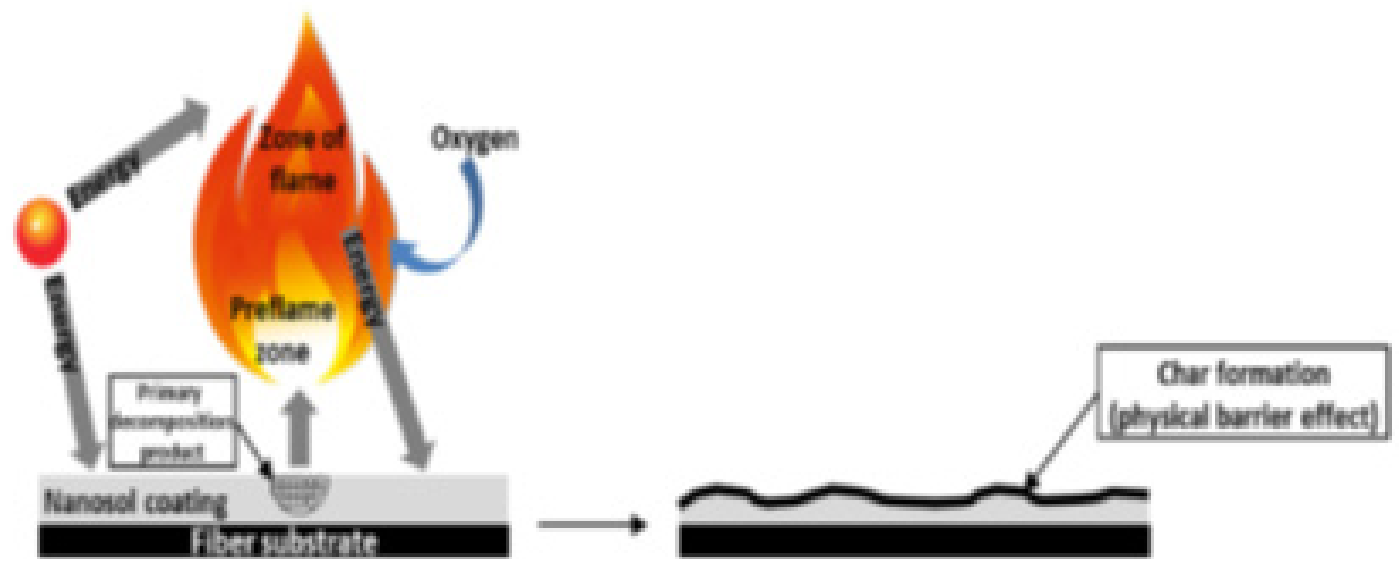

Fig. 5. Fire-retardant mechanism of nanosol-treated fabric

J. Text. Color. Polym. Sci. Vol. 18, No. 1 (2021) 
Self-cleaning has shown the photocatalytic action of a matter, which uses light (photo) to initiate a matter that changes the speed of a chemical action without being involved by itself (catalysis) [32]. The self-cleaning procedure is showed in Fig. 6. within the attendance of sunshine and humidity within the air, the active oxygen is created on the surface of the material coated with the nanoparticle and when the organic compounds get contact with the active oxygen, it's oxidized and decays into harmless carbonic acid gas and vapour ${ }^{29}$. Photocatalytic self-cleaning materials contain $\mathrm{CdS}, \mathrm{SnO}_{2}, \mathrm{ZnO}$, and $\mathrm{TiO}_{2}$. The last metal oxide is most preferred from these matter because of its properties as chemical stability, low cost , non-toxicity, durability contrast to corrosion ${ }^{30}$.

Ibahim et al. ${ }^{31}$, Improve the printability and functionality of linen / cotton fabric by combining nanomaterials such as titanium dioxide (TiO2 -NPs), zirconium oxide ( $\mathrm{ZrO} 2$-NPs), zinc oxide ( $\mathrm{ZnO}$ NPs) and silver (Ag- NPs) in a solvent-free pigment printing paste. This process occurs in one step. The improved functions of anti-bacteria in linen / cotton fabric and also keep track of the order of TiO2-NPs $>$ $\mathrm{ZrO} 2-\mathrm{NPs}>\mathrm{ZnO}-\mathrm{NPs}>\mathrm{Ag}-\mathrm{NPs}$ without changing other parameters. But the UV protection ability of print fabrics followed the order: $\mathrm{ZnO}-\mathrm{NPs}>\mathrm{TiO} 2-$
NPs $>$ ZrO2-NPs $\geq$ Ag- NPs NPs $\geq$ none unprinted.

The values of K/S and fastness properties of printed fabrics are controlled by kind of pigment colorant and binding agent as well as the type of nanomaterials additive. New characteristics acquired with the depth of dyed prints obtained are stable and durable, the direction of repeated washing (20 cycles). Thus highly effective durable antibacterial and anti-UV protection and high color strength linen/cotton prints can be produced with a fairly simple product. The developed pigment printing method has industrial potential.

When using chitosan $(10 \mathrm{~g} / \mathrm{kg})$, triclosan derivative (20 g / kg), choline chloride (15 g / kg), HBPAA / ZnO-NP or HBPAA / Ag-NP hybrid (20 g / kg) with the printing paste for printing cotton fabrics and using the microwave to fixed color at $386 \mathrm{~W}$ for $5 \mathrm{~min}$. Higher color strength values and improvement of antibacterial activities are achieved. the proportions of enhancement in the printability and antibacterial effect for cotton fabric is subject to performance according to the kind of antibacterial auxiliary and its concentration, kind of binding and coloring agent. It is found that the printing samples have the excellent antibacterial activity with higher color strength and soft handle for 20 washing cycles $^{32}$.

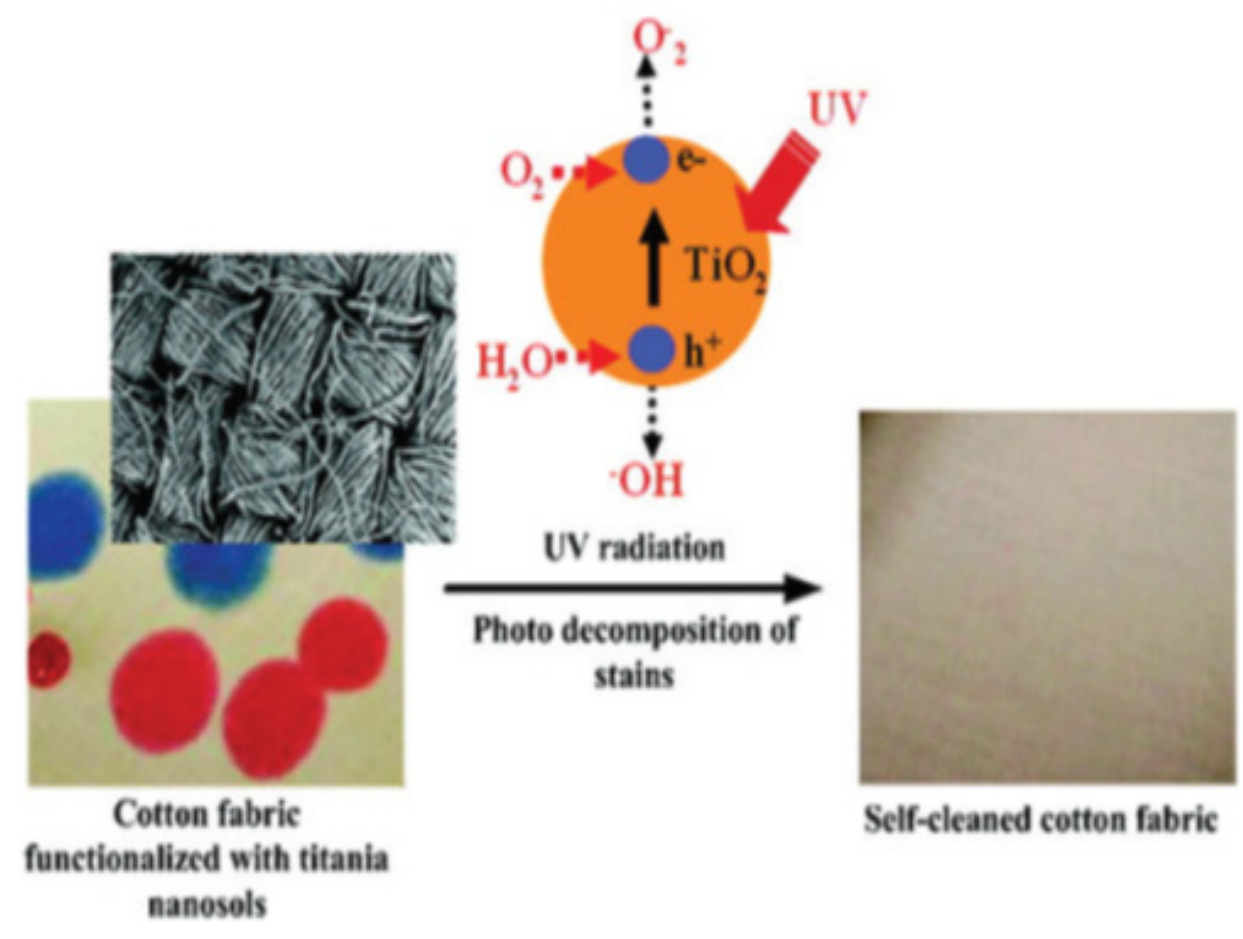

Fig. 6. Self-cleaning mechanism of of cotton fabric treated with titania nanosols. 

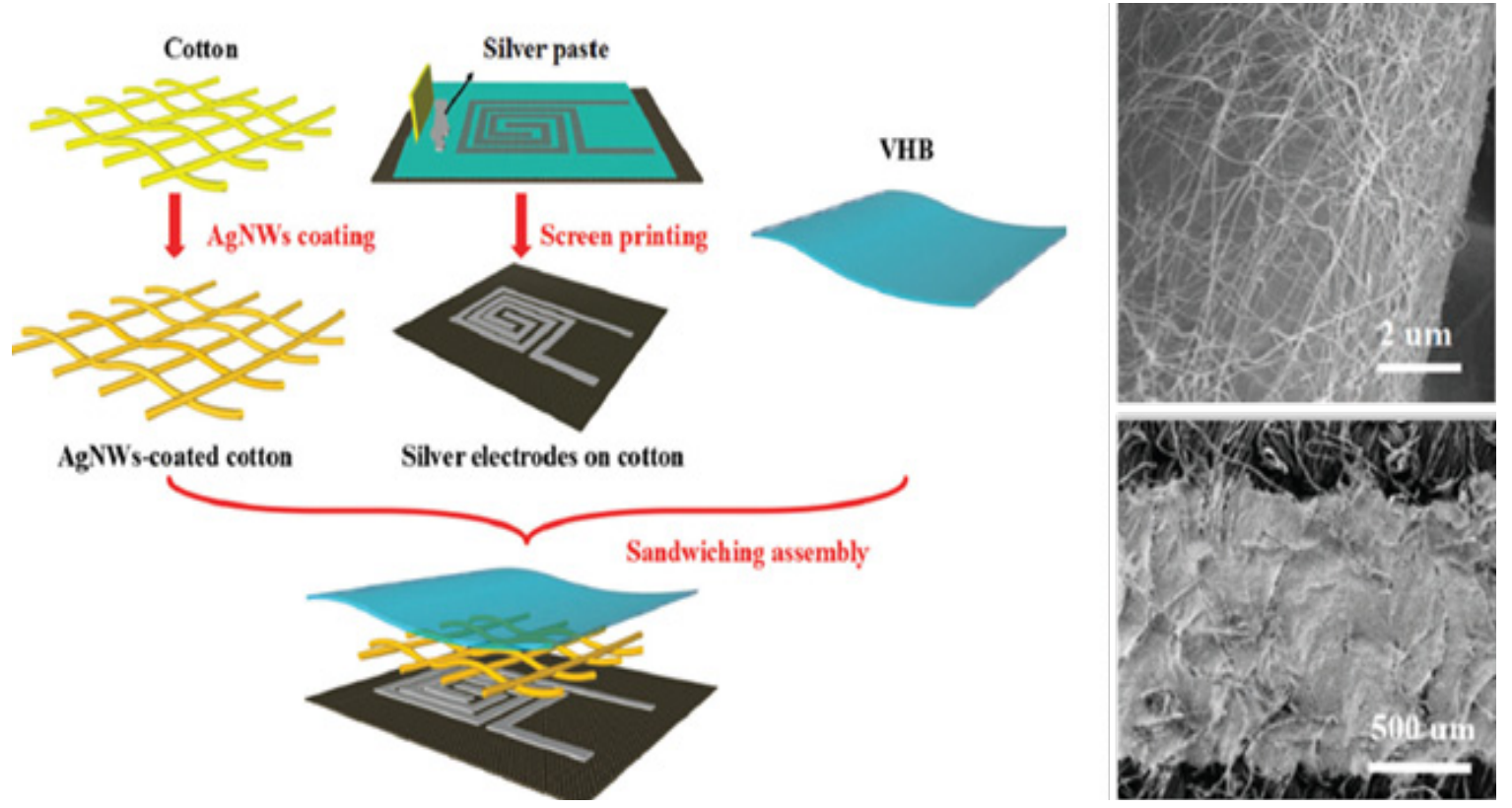

Fig. 7. Supersensitive of printing fabric coated AgNps.

\section{Magnetron Sputter Coating}

The magnetron sputtering is one in every physical vapor deposition (PVD) methods which might deposited nanometal or nanometal oxide membrane on the surface materials of textiles fabric through selecting the acceptable sputtering process. ${ }^{33},{ }^{34}$. Magnetron sputtering operations have the advantages of controlling the thickness of the membrane which has low temperature, high speed, proper adhesion, a high purity, easy operation, and environmental friendliness ${ }^{35},{ }^{36}$.

Magnetron sputter deposition is a vacuum technique that applied high power via lowpressure gas to form active gas particles. Through the process coating, the gas particles interactive with object and cause the transmission of atoms from the object to the materials ${ }^{37},{ }^{38}$.

\section{Some of the sputtering attack materials as}

\begin{tabular}{|l|l|}
\hline Metals & $\begin{array}{l}\mathrm{Cu}, \mathrm{Ti}, \mathrm{Ag}, \mathrm{Al}, \mathrm{W}, \mathrm{Ni}, \mathrm{Sn} \\
\mathrm{Pt}\end{array}$ \\
\hline Non-Metals & $\mathrm{Si}$, graphite \\
\hline Metal oxides & $\mathrm{TiO}_{2}, \mathrm{Fe}_{2} \mathrm{O}_{3}, \mathrm{ZnO}$ \\
\hline Non-Metal oxide & $\mathrm{SiO}_{2}$. \\
\hline
\end{tabular}

The textile fabrics coated with metal or metal oxide by using magnetron sputter technique to gain them new different properties like anti-static, ultraviolet resistance, antibacterial, gas sensitivity, electrical conductivity, electromagnetic shielding

J. Text. Color. Polym. Sci. Vol. 18, No. 1 (2021) and improve the fastness properties of dyeing and printing fabric ${ }^{39},{ }^{40}$.

Magnetron-sputtering device is used in the deposition of $\mathrm{Ag} / \mathrm{TiO}$ nanocomposite on the surface of polyester fabric. The produced surfaces are one golden yellow and the other yellow, Fig. 8. The difference in their colors is depending on the thickness of $\mathrm{TiO}_{2}(60 \mathrm{~nm}$ and $62 \mathrm{~nm})$ in $\mathrm{Ag} /$ $\mathrm{TiO}_{2}$ composite films. The created coated fabrics membrane $\mathrm{Ag} / \mathrm{TiO}_{2}$ has resistance to static electricity and the characteristics of anti-bacterial properties, and the anti-property UV better than the untreated polyester fabrics ${ }^{41}$.

To improve the electrical conductivity and electromagnetic shielding properties for cotton fabric, ${ }^{34}$ it was coated with polyvinyl alcohol (PVA), and then, $\mathrm{Ti}$ or $\mathrm{Cu}$ was sputtered and deposited on the cotton surface. ${ }^{34}$. Fig. 9 shows the formation of the PVA membrane on the surface of cotton fabric by padding and a sputtering method ${ }^{42}$.

\section{Layer-By-Layer ( $L B L$ ) technique}

Layer-By-Layer (LBL) methods are used for the synthesis of a thin membrane, most of which are the organic structures that include functional groups, and are created to modify the surface properties of many materials. This technique is considered another method for manufacturing nanolayers depended on the concept of selfassembled nanolayers ${ }^{43}$.

The principle of LBL technology consists of 
the deposition of layers of the opposite charged electrolyte, which interact with each other due to the electrostatic forces. This leads to the modification of multi-component molecular assemblies and control of molecular structure with a large percentage of thickness control ${ }^{44}$. In the LBL method, the adsorption treatment is followed by a rinsing stage to remove any contamination with the next adsorption solution. The outer

(a)
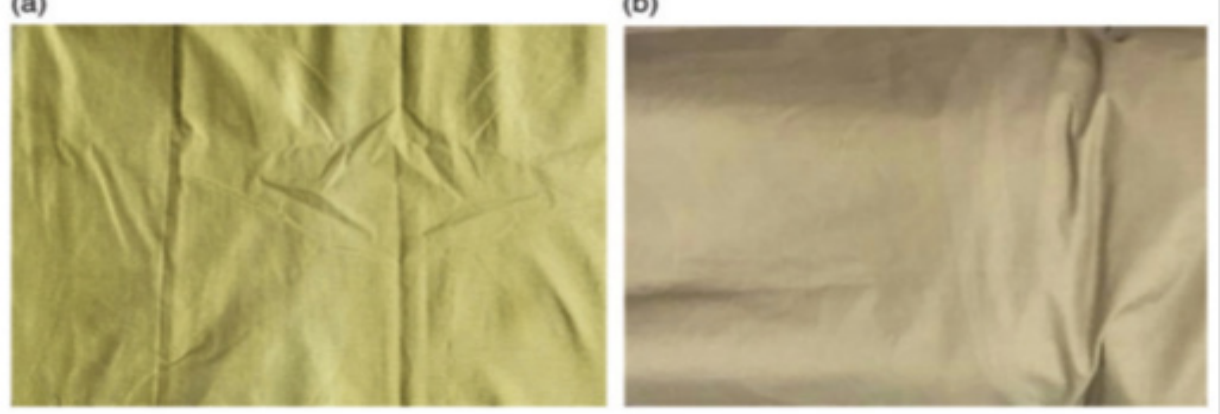

Fig. 8. Color strength of polyester fabrics coated with $\mathrm{Ag} / \mathrm{TiO} 2$ particles (a) prepared with thickness of $\mathrm{TiO} 2$ (60 $\mathrm{nm})$ (b) prepared with thickness of $\mathrm{TiO} 2(62 \mathrm{~nm})$ by using magnetron sputtering.

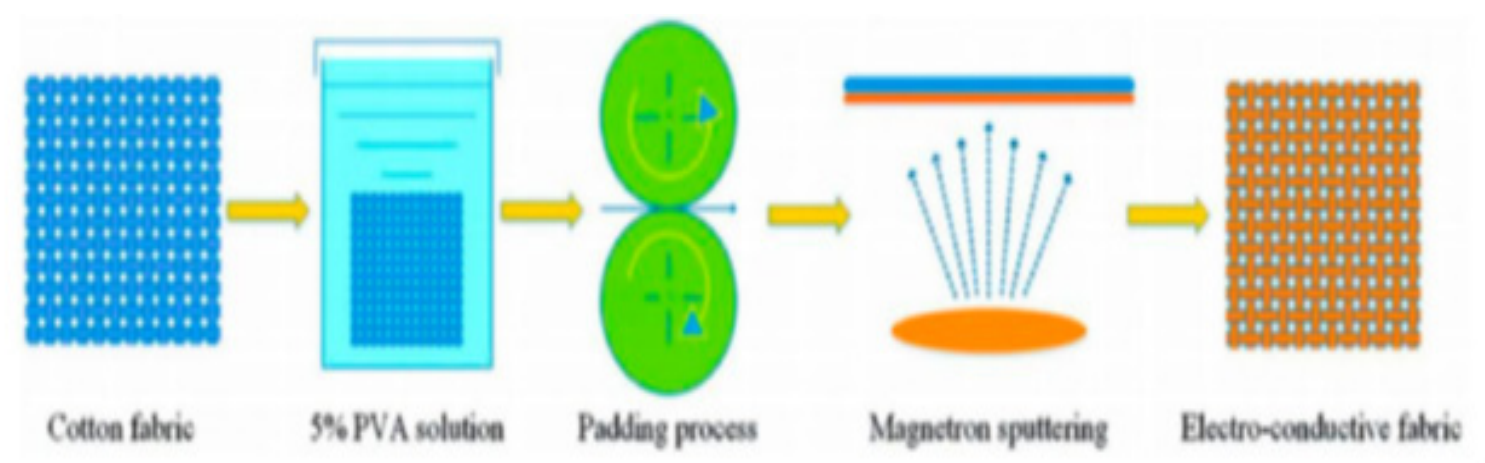

Fig. 9. Diagram show the formation of PVA film on cotton fabric by padding and sputtering ${ }^{42}$.

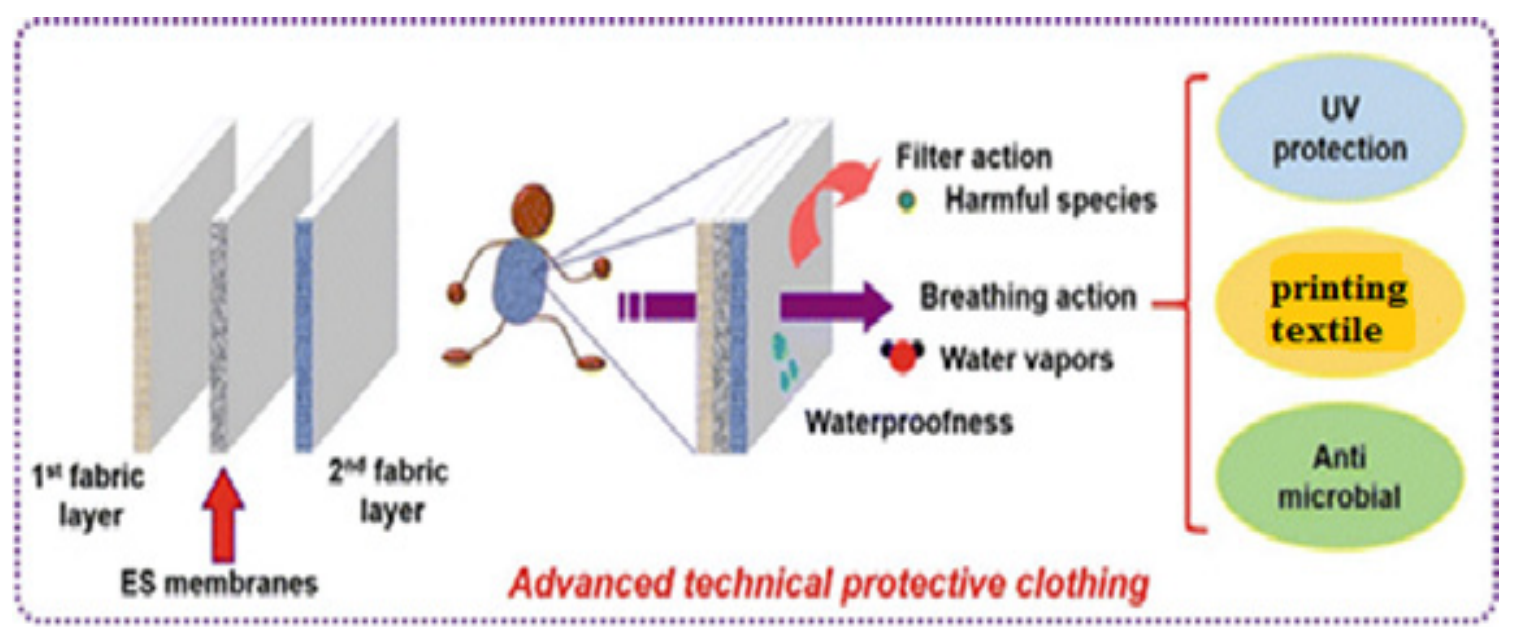

Fig. 10. Layer-by-layer assembly for fabrication of thick polymeric clothing and its application in printing textiles. 
In LBL processes, cationic places are generally created on the treated surface fabric and used in the deposition of nanoparticles. On cationic cotton, the 2, 3-epoxy propyl tri-methyl ammonium chloride (EP3MAC) are react with hydroxyl groups in cotton fabric to form cationic group on the surface fabric. In the deposition process, the cationized surface of cotton fabric was immersed respectively in (a) anionic $\mathrm{ZnO}$ solution, (b) deionized water, (c) cationic $\mathrm{ZnO}$ solution, (d) deionized water to result a textile has the ability to resist bacteria and protection from UV ${ }^{47}$.

The LBL method has a great role in the K/S improvement. It is applied for the nonwoven polyamide fabric where, the deposition of direct red dye and poly (diallyl di-methyl ammonium chloride) (PDADMAC) on the fabric is carried out, giving improved color strength results. It was found that the increase of $\mathrm{K} / \mathrm{S}$ at $510 \mathrm{~nm}$ is increased linearly with the number of layers, while any additional increase in PDADMAC concentration led to a decline in the value of $\mathrm{K} / \mathrm{S}$. Besides, the LBL method is also improving the color fastness properties for dyed silk fibers using natural dye by depositing alternate layers of poly (ammonium chloride Dithil) and polyethylene (Slfatunat styrene) (PSS) (up to 30 layers). Then, examine the surface structure using ATR FTIR and observe the exhaustion dyed silk fibers by using UV ultraviolet spectroscopy ${ }^{48},{ }^{49},{ }^{50}$.

\section{Nanomaterial embedded textile}

The nanomaterials have to be compelled to be mounted against laundry, it should be inserted to preserve the great value and practicality of the textiles product. These additionally, prevent the discharge of the potential risks of nanomaterials on human health and also the surroundings.
Therefore three totally different techniques are projected to embedding particles on the fiber compound matrix to convey a superior with nice benefits of textile materials.

The $1^{\text {st }}$ Technique: a cross-linking agent is employed to capture nanocomposites. Cross linkable polymers like binders and chitosan are approached for this objective ${ }^{51},{ }^{6},{ }^{52}$. Mabrouk et al could successfully prepared polyurethane acrylate (PUA) and using as binder to improvement printability of silk fabric. This binder was used with $\mathrm{TiO}_{2}$ nanoparticles in preparing an ink which could be used in printing pastes for coloring silk material and improving its wrinkle resistance properties, UV-protection and anti-bacterial activity $^{53}$. Increasing he $\mathrm{TiO} 2$ nanoparticles concentration affected the increase of $\mathrm{K} / \mathrm{S}$ of the printed silk fabric where $\mathrm{TiO} 2$ nanoparticles catalysis the speed of polymerization reaction of the binder during the unsaturated reaction, leading to extra pigment fixation which in-turn increases the color strength.

The $2^{\text {nd }}$ Technique: Associate in nursing in situ synthesis of nanoparticles on the fabric so on extend the stableness of nanoparticles has been used as an alternate methodology of fixation ${ }^{54}$. In situ synthesis of silver nanoparticles in boiling purpose controlled to stabilized nanoparticles on the cotton material. Wherever, the synthesis method within the boiling temperature light-emitting diode to the swelling of the fiber molecular chain then assumed that the nanoparticles are measure designed and permeate the material structure and stayed there when treatment ${ }^{54}$. During this approach, has been found that the antibacterial efficiency and durability of cotton materials were improved.

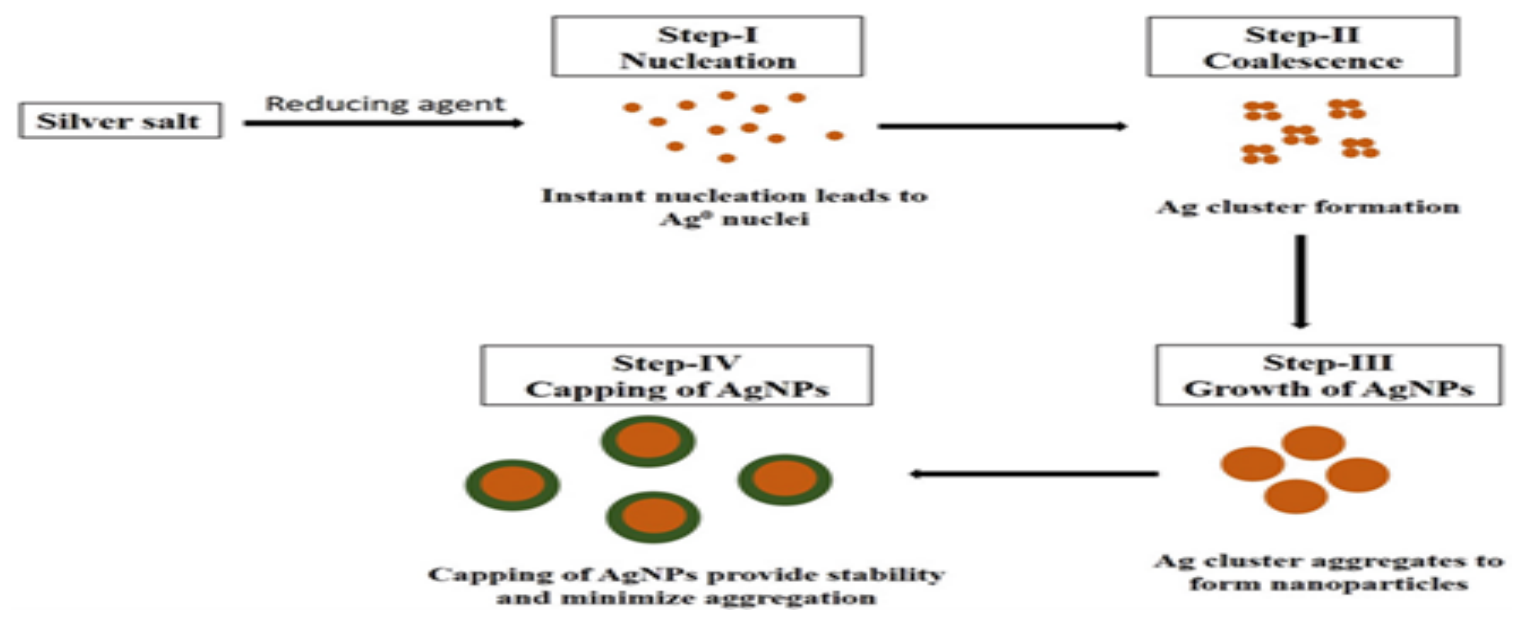

Fig. 11. Schematic representation of various step of development of silver nanoparticles.

J. Text. Color. Polym. Sci. Vol. 18, No. 1 (2021) 
The $3^{\text {rd }}$ Technique: includes nanoparticles embedding within the fiber chemical compound matrix using carboxyl acid, a replacement methodology with noticeable benefits ${ }^{55},{ }^{56},{ }^{57}$. Silver nanoparticles are stabilized on the material by using polysiloxan as a linker to accumulate the textile surface several properties like softness, flexibility ${ }^{51},{ }^{58}$. Moreover, binders are using to enhance the stability of silver nanoparticles and $\mathrm{ZnO}$ on the surface of textiles materials ${ }^{52}$.

\section{Plasma Nano coating}

Textile conventional wet-chemical processing techniques are very essential for textile industries field, and according to environmental regulations, they caused prolusion and are considered harmful for many reasons. Plasma treatment technology has attracted more attention in the textile industry and sounds to be great alternative to these conventional wet-chemical techniques. As a new technology, in recent years, it has many advantages; a relatively simple process that is clean, solventfree, time saving, and environmentally friendly. Moreover, plasma treatments is a physical surface technique that offers the possibility to obtain typical textile finishing without changing the bulk textile properties and plasma can be used for ablation and deposition processes ${ }^{59}$. Ablation enables a complete cleaning of textiles from manufacturing residuals, while, deposition can be controlled in the nanometer range to achieve new functionalities. The efficiency of plasma treatment depends on many factors such as the nature of the substrate and the treatment operating conditions; discharge power, plasma gas type, exposure time and device of plasma used. However, the application of plasma technology to different kinds of textile materials is not fully exploited. Textiles with functional coatings are required for the manufacture of sports and recreational clothing, protective clothing, barrier textiles, medical or hygiene textiles or for membrane in the context of textile architecture.

\section{Plasma Basics and Fundamentals Definition}

Plasma is a group of different charges negative and positive which behave collectively. The charges Coulomb's forces influence the forces applied externally and control the effects of collisions between charges themselves and any present neutral gas ${ }^{60}$. One of the main results, is the plasma ability to detect local density disturbances and form a sheath area between the plasma and the adhered surfaces.

\section{Generation}

Plasma is formed by applying energy to the gas $^{61}$ to reorganize the electronic structure of atoms and molecules species and the production of ion species. The applying energy can be transportable radiation or electromagnetic current, or thermal energy. All these sorts of energy are moving under electromagnetic fields. In case of passing textile substrates within plasma, various processes are carried out; breaking the links forming active sites, creating new functional groups, disintegration of contaminants/ surface layers (etching / Ablation) and deposition of corresponding coating ${ }^{62}$.

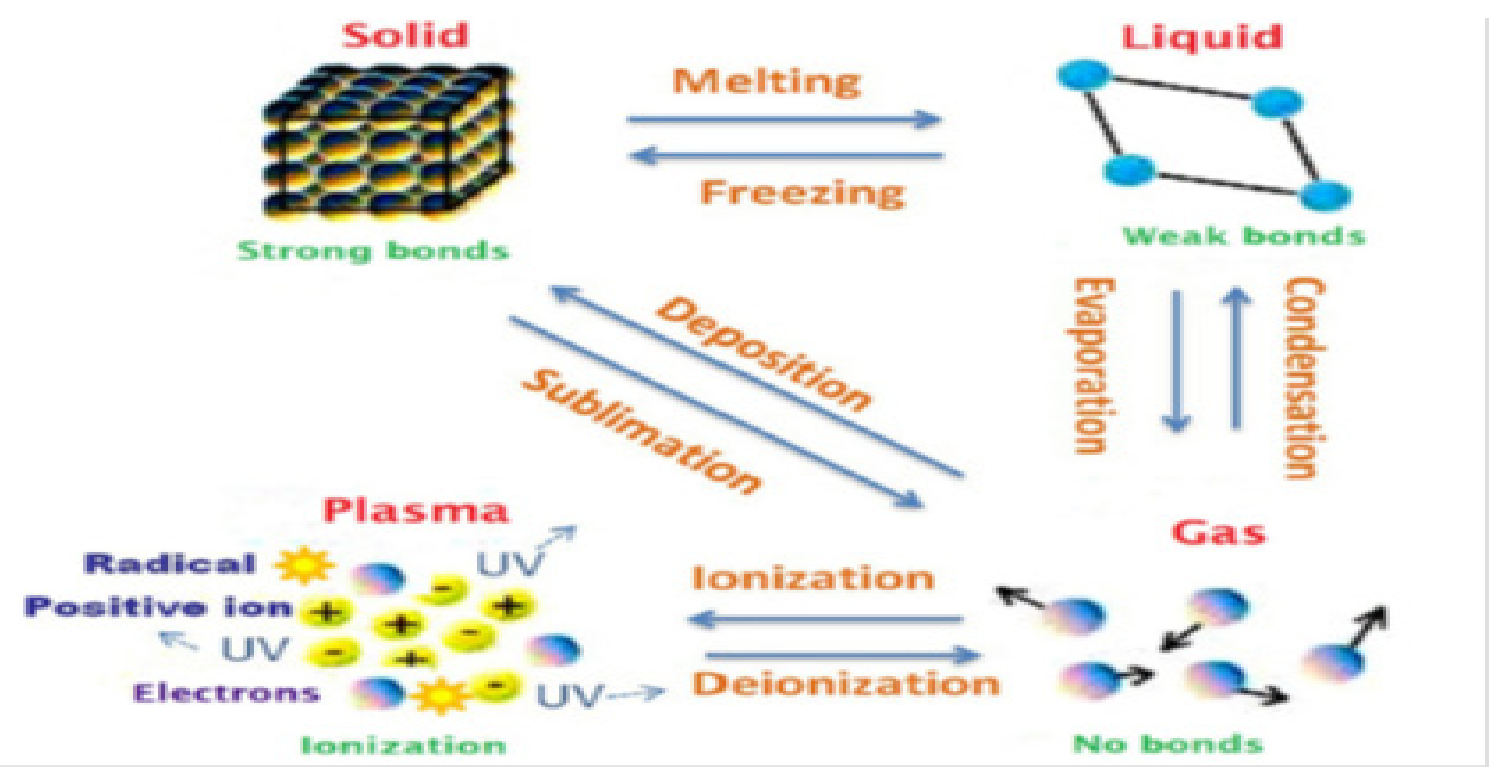

Fig. 12. Fundamental of plasma 


\section{Classification}

Plasma could be classified into thermal and cold plasmas depending on plasma temperature. In thermal plasma or hot plasma, all components are in equilibrium, i.e., temperatures of electrons and different particles are too high whether charged or neutral, that is close to the maximum ionization (approximately 100\%) ${ }^{63},{ }^{64}$. Thermal plasmas includes electrical arcs, plasma jets, and thermonuclear reaction-generated plasma. Nonthermal plasmas (Cold) are corona discharge, low-pressure direct current (DC), discharges from fluorescent (neon) enlightening tubes, radio frequency (RF) discharges (silent discharges), and dielectric barrier discharge (DBD) ${ }^{65}$.

\section{Using of plasma treatment in textiles field}

Principles of plasma process

Great chemical and physical transformations were occurred for textile materials by plasma treatments. These transformations include chemical and structural changes of surface layers and their physical properties ${ }^{66},{ }^{67}$. During plasma treatments, electron collisions and photochemical processes cause molecules disassociating and formation of high density of free radicals. These lead to chemical bonds disruption within the fiber polymer surface, ending up with the creation of recent chemical groups. The surface activated and its topography area are affected as well as the specific surface area of fibers is significantly enlarged. New functional groups like $-\mathrm{OH}$,$\mathrm{C}=\mathrm{O},-\mathrm{COOH}$ are produced and influencing the fabric wettability in addition to facilitate graft polymerization. Plasma can bring several effects to substrates, such as surface fine cleaning, activation and etching of fabric surface, crosslinking and coating deposition that depending on the plasma mode and the process gases used ${ }^{68}, 69$.

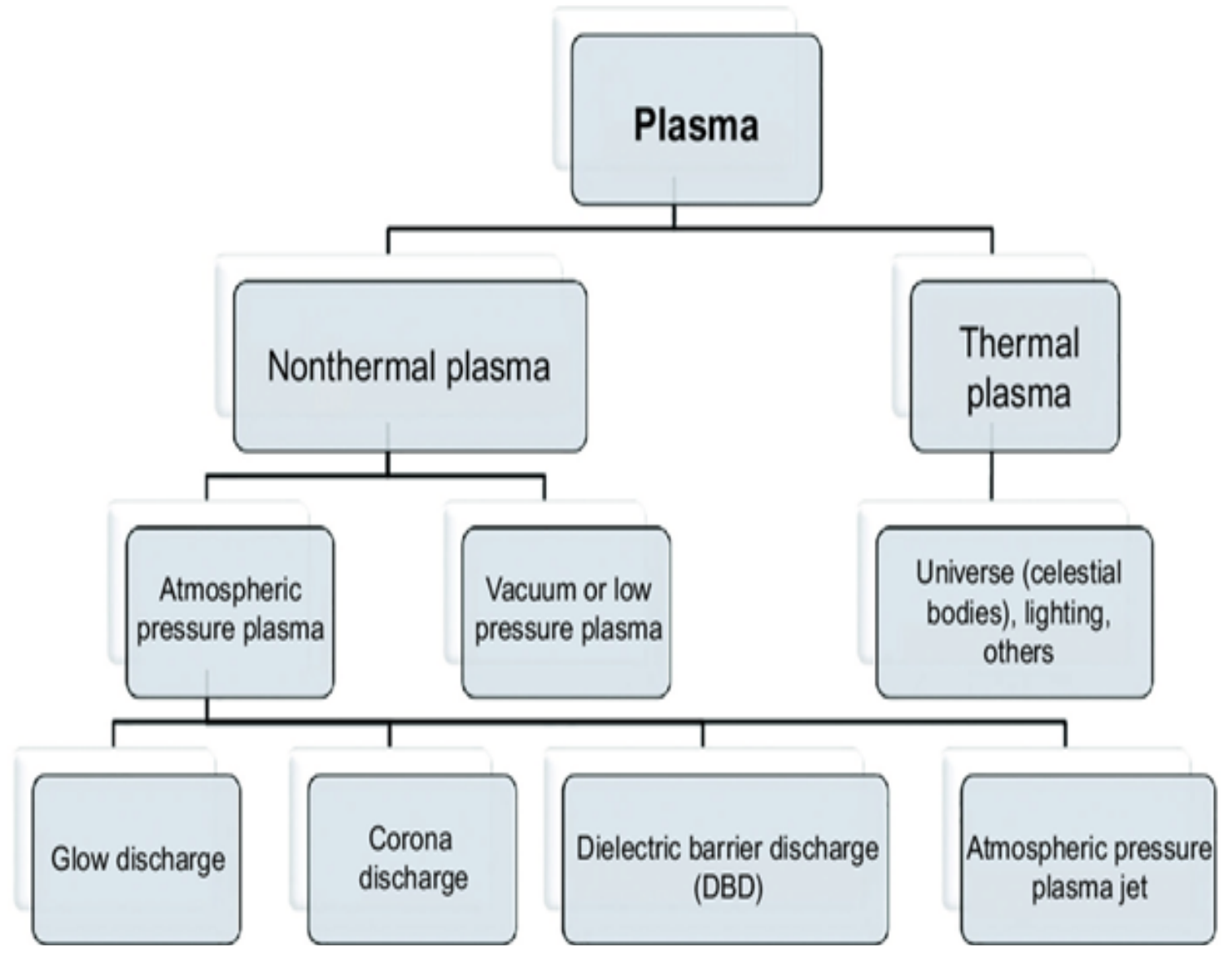

Fig. 13. Different plasma categories 


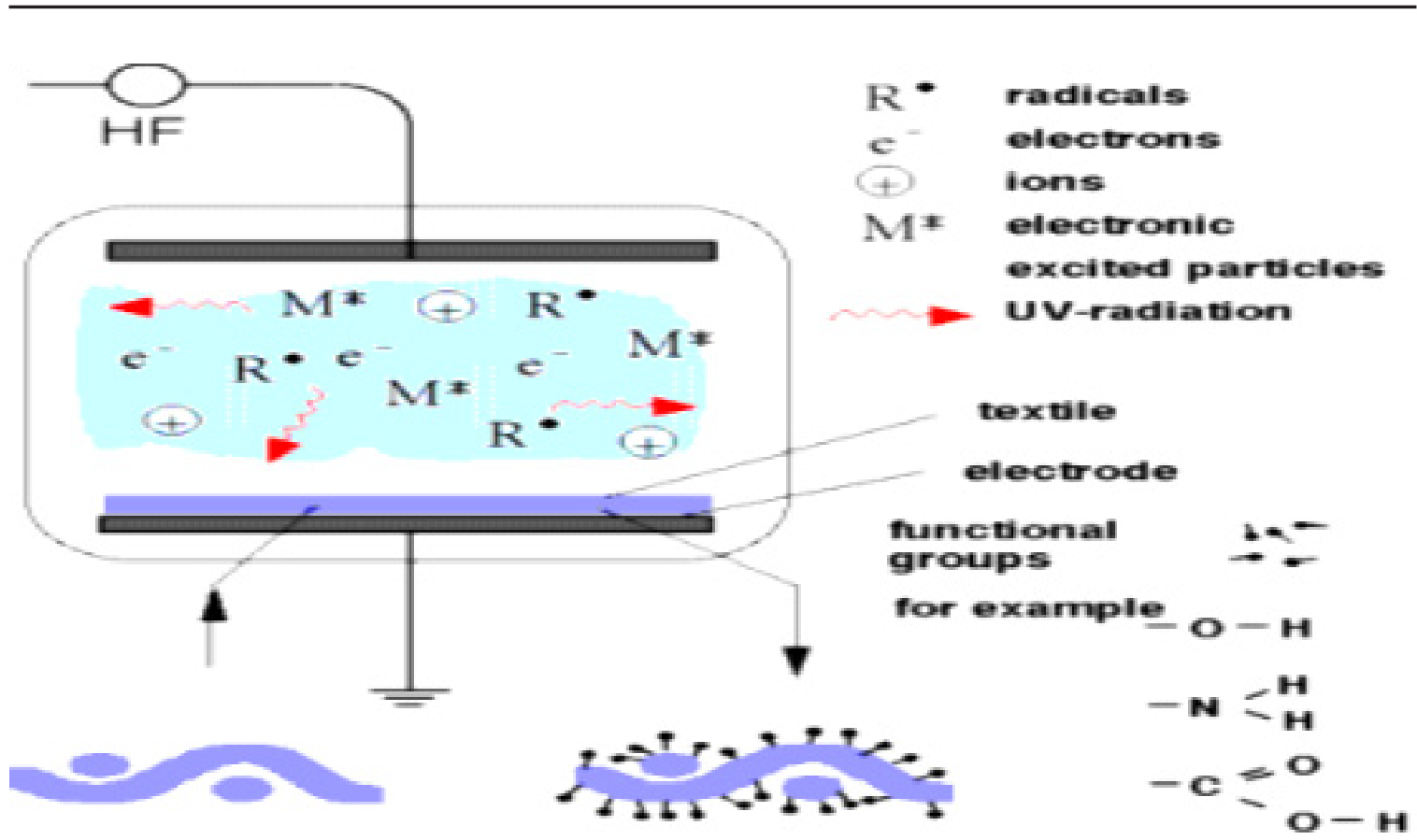

Fig. 14. Principle of plasma treatment ${ }^{70}$.

Active Plasma Species Interaction with Textile Surface:

Plasma treatment aims to introduce new functional groups to the textile surfaces and change their chemical compositions without influencing the bulk properties of fabrics. The surface treatments usually occur in a depth of few hundred astronomy ${ }^{71}$. Plasma leads to a formation of charged particles e.g. ions and electrons. Moreover, atoms/ molecules, met stables and free radicals are presenting in the active plasma region, as well as photons (due to the UV light generated). All these particles interact differently with the substrate, resulting in a many of various surface processes. Plasma process will alteration hydrophobic surface to hydrophilic and contrariwise, addicted to the gas / chemical compound kind used in generating plasma. It can also, improve the wettability or water repellency, depending on whether, the chemicals have been converted/ rounded or shifted on the surface of the textiles.

\section{Plasma cleaning and etching}

Plasma surface etching is a category of plasma action applied to increase the surface area of substance on the microscopic measurement. The surface of the element is more rough with a reactive process gas.

During materials production, they can be showing to a number of contaminants; solvents, grease and components of volatile substances, etc. These contaminants will be absorbed and accumulated on the surface of materials with time, leading to a surface change and non-proliferation with low likely performance of the product. The prolonged exposure of the plasma will not only lead to the removal of pollution has intensified, but also will lead to the drilling of the upper layers of the matter surface dependent on the density \& hardness of the exposed material ${ }^{72},{ }^{73},{ }^{74},{ }^{75}$. As for the bio-medical textiles which are made in most cases of a relatively soft material, it cannot supervise the impact of drilling and will present certain roughness nanoscale on the surface of the fiber $^{76},{ }^{77},{ }^{78}$.

Cotton fabric was treated by DBD atmospheric plasma using air and oxygen at various discharge powers for different periods of time and the printed treated fabrics were gained high $\mathrm{K} / \mathrm{S}$ values. Oxygen plasma treatment is more effective than air plasma treatment on the surface etching of cotton giving higher $\mathrm{K} / \mathrm{S}$ compared to air plasma where it depends more on the oxygen component of the air than on the nitrogen component, which supports an oxidative mechanism of attack of cotton. Generally speaking, possible contributory factors leading to the increase in color strength for air and oxygen plasma treated cotton are owing to the chemical changes of cotton surface due to the oxidative attack on the cellulose forming both carbonyl and carboxyl groups in the fiber. Besides that, the probability of free radicals on the cellulosic chains of cotton via oxygen and air plasma treatment. [83]

J. Text. Color. Polym. Sci. Vol. 18, No. 1 (2021) 


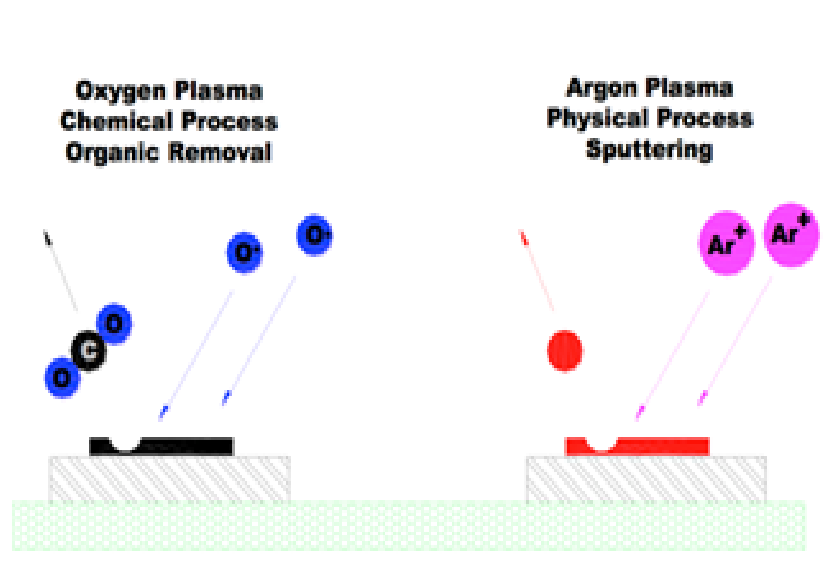

Fig. 15. plasma cleaning processes.

\section{Plasma activation}

Activated plasma or perform may be a way to modify the surface of materials. employing a plasma treatment is improves adhesion properties of the surface of the various materials together with metal, glass, ceramics and a decent vary of polymers, textiles and even natural materials like wood and seeds. The plasma perform conjointly indicates the introduction of purposeful group to the surface of exposed materials [75]. Plasma process achieved among the activated surface of matter by combination of reduction of metal oxides, ultra-fine surface cleansing from organic contaminants, and modification of the surface topography and deposition of purposeful chemical group [84]. Sure, there are measure alternative strategies instead of plasma activation that may generate new functional group to a surface, however since its non-metaphorical and chemical-free; it ensures that the foremost sensitive structures are measure preserved [85].

The influence of air plasma exposure time and discharge power on the relative color strength $(\mathrm{K} / \mathrm{S})$ of polyester prints were studied. The results cause a good most worth of improvement within the color strength compared to the untreated polyester prints. the big distinction in color strength values before and when plasma treatment powerfully indicates that plasma causes a crucial amendment to polyester material wherever, it creates several reactive species like free radicals and forms new polar group that created the polyester material a lot of accessible to water and dye molecules. Thus, it improved the wettability and diffusion of dye molecules that in-turn will increase the colour strength of the treated written samples [86].

J. Text. Color. Polym. Sci. Vol. 18, No. 1 (2021)

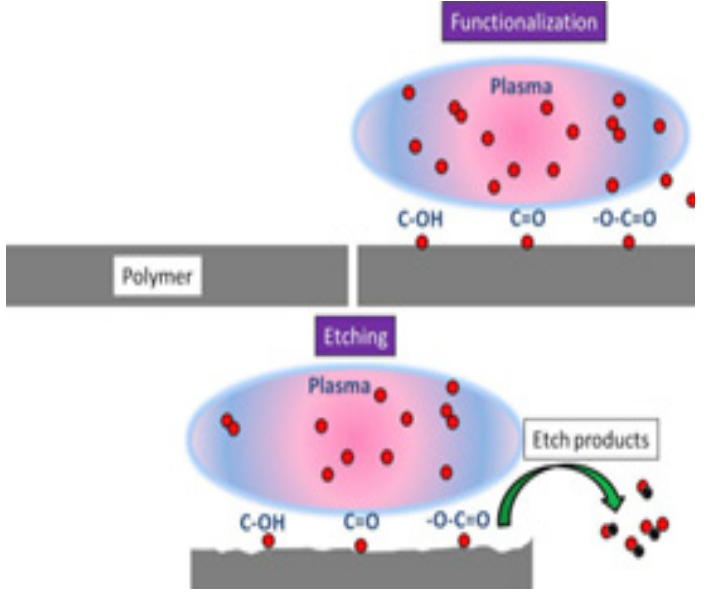

Fig. 16. plasma etching processes.

Rashed et al, conjointly studied the impact of oxygen gas plasma exposure time on the color strength of the printed polyester material and it was found that, the time needed to obtain maximum results of color strength is shorter than in case of air plasma alone, which may be due to the presence of more oxygen that activate the surface more rapidly and obtain better results at shorter time.

\section{Plasma grafting and polymerization}

The non-thermal plasma has other application rather than plasma treatments such as starting radical polymerization that leads to a deposition of wide ranges of thin films. In order to improve the bonding between these thin films and biological materials, the deposition process takes place in plasma, which offers radical sites, and allows the covalent polymer in conjunction with the surface of the substrate. The polymers can deposit on the surface placing in between the two electrode. Polymerization process can occur by ionic or radical process which is initiated by plasma generated by glow discharge. Plasma is used as a methods to initiate and remain the activation during the entire reaction polymerization that leads to the development of initiation locations on both the substrate surface and the monomer. Moreover, plasma can be used for many functional groups of polymeric precursors to initiate the chain reaction. Highly cross-linked, and amorphous thin film is usually obtained by using the plasma initiation that differ from its traditional equivalent and adheres to wide range of surfaces. The amount of functionalities present in the film is highly controlled by the discharge power change ${ }^{79}$.

Plasma-induced graft polymerization of diallyl group dimethyl salt (DADMAC), a quaternary ammonium ion salt chemical compound on 50/50 
Nylon-Cotton (N/C) customary. Air pressure glow discharge plasma is utilized to induce atom chain polymerization of the DADMAC chemical compound to introduce a graft-polymerized network on the fabric with sturdy antimicrobial properties. medicament performance is investigated victimization customary AATCC take a look at technique a hundred for each grampositive and gram-negative bacteria ${ }^{80}$.

Atmospheric pressure glow discharge plasma (APGD) was applied on acrylic fabric using two methodologies. The $1^{\text {st }}$, methodology was disbursed via two techniques; first, treating the acrylic cloth by plasma, printing, and so fixing by steaming, 2nd, the untreated acrylic cloth was written followed by fixation with plasma. The second methodology was treating the acrylic cloth with Plasma followed by hydroxylamine. The APGD plasma treatments of acrylic cloth caused the activation of acrylic surfaces that end up in up the acrylic cloth properties. The morphological studies for the treated acrylic cloth surface showed that treatment with plasma followed by chemical action with hydroxylamine complex made a changed acrylic cloth had the flexibleness to be written with acid and reactive dye giving higher color strength values, and sensible fastness properties. Characterization of acrylic samples once treatment could facilitate in selecting the best conditions of plasma treatment and its relation with the assorted properties of the fibers. ${ }^{81}$.

Plasma co-polymerization and Nano coating of textile

The most popular technique of nanoparticles deposition on textile materials surfaces is pad-drycure technology ${ }^{82}$. The influence of pad-dry-cure and exhaustion methods on adhesion activity and anti-microbial materials using silver nanoparticles and technical organic - inorganic binder was investigated ${ }^{83}$. The results displayed that using of the pad-dry-cure method for loading the fabric with silver nano-particles led to low amount of the nano-particles deposition compared to the amount deposited on the fabric using exhaustion technique. Application of silver nano-particles on textile substrates can be obtained by plasma polymerization method where the fabric surface run using silver microfilm through sputtering ${ }^{84}$.

Higher adhesion properties in the direction of metal or nanoparticles on substrates could be achieved due to the increase in the fiber surface roughness caused by plasma etching ${ }^{85},{ }^{86}$. Adhesion of TiN (titanium nitride) to polypropylene (PP) and polycarbonate (PC) was occurred once modifying the substrates with low-pressure argon plasma due to the increase of the surface roughness. ${ }^{87}$. Polyester polymer surface was improved to optimize the attachment of materials to fucoidan that is -biologically active materials with anti-clotting properties, where the adhesion of fucoidan to materials' surfaces was enhanced by oxygen plasma treatment due to the increase in roughness surface of substance. And the adhesion action, surface energy and surface polarity of polyamide 6 (PA6) fibers were enhanced by using electrical barrier discharge (DBD) in helium gas at atmospheric pressure. The DBD plasma is environmentally friendly dry technology modifies the surfaces of the fabric evenly without traditional chemical procedures ${ }^{88}$. Active plasma processing DBD fabric surface by introducing new functional groups e.g. carboxyl and carbonyl, ether, amine and hydroxyl is depending on the used gas (such as air, helium, nitrogen or oxygen). These polar groups have the ability to increase the surface energy and therefore, exchanging the wettability of fabric. Also it can enhance the etching and cross linking, without affecting the material bulk properties ${ }^{88}$. In addition, plasma processing for the deposition AgNPs is attractive due to the formation of roughness surface linked to chemical changes on the surface that improves installation AgNPs. The deposit AgNPs on various parts of the textile material is inaccessible mechanically by physical attraction such as Van der Walls or electrostatic forces ${ }^{89}$.

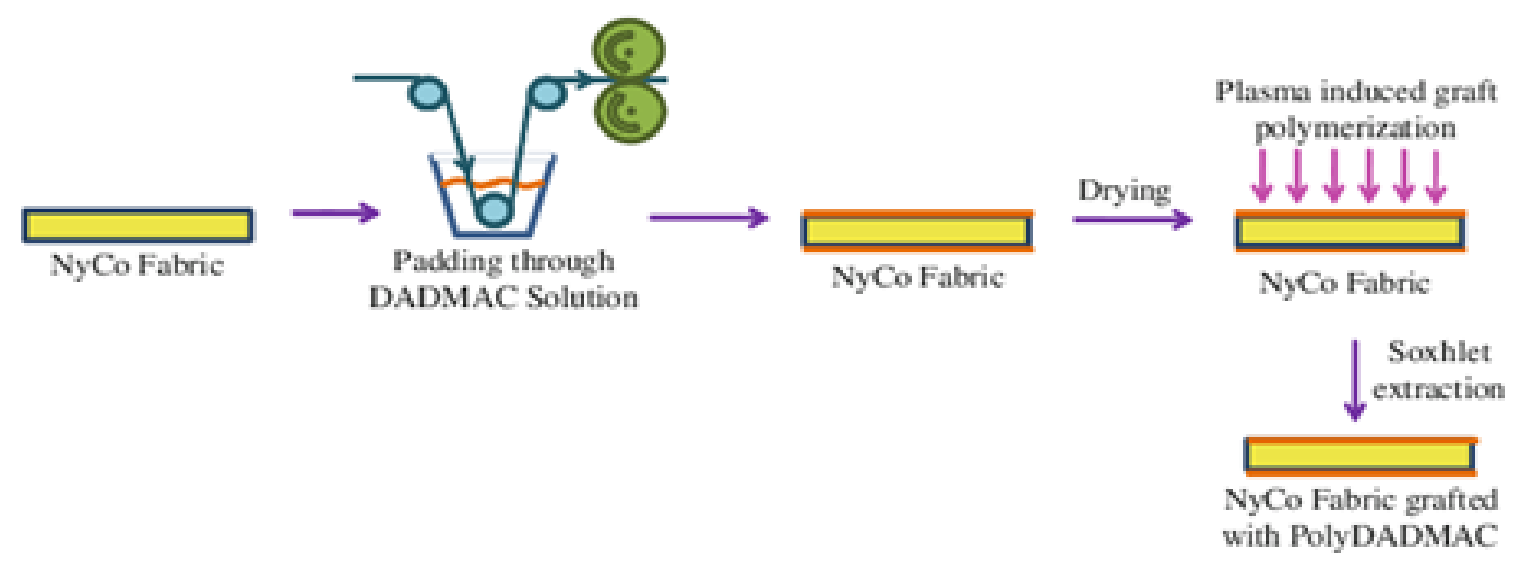

Fig. 17. Plasma induced graft polymerization of DADMAC on nylon/cotton (N/C) fabric. 


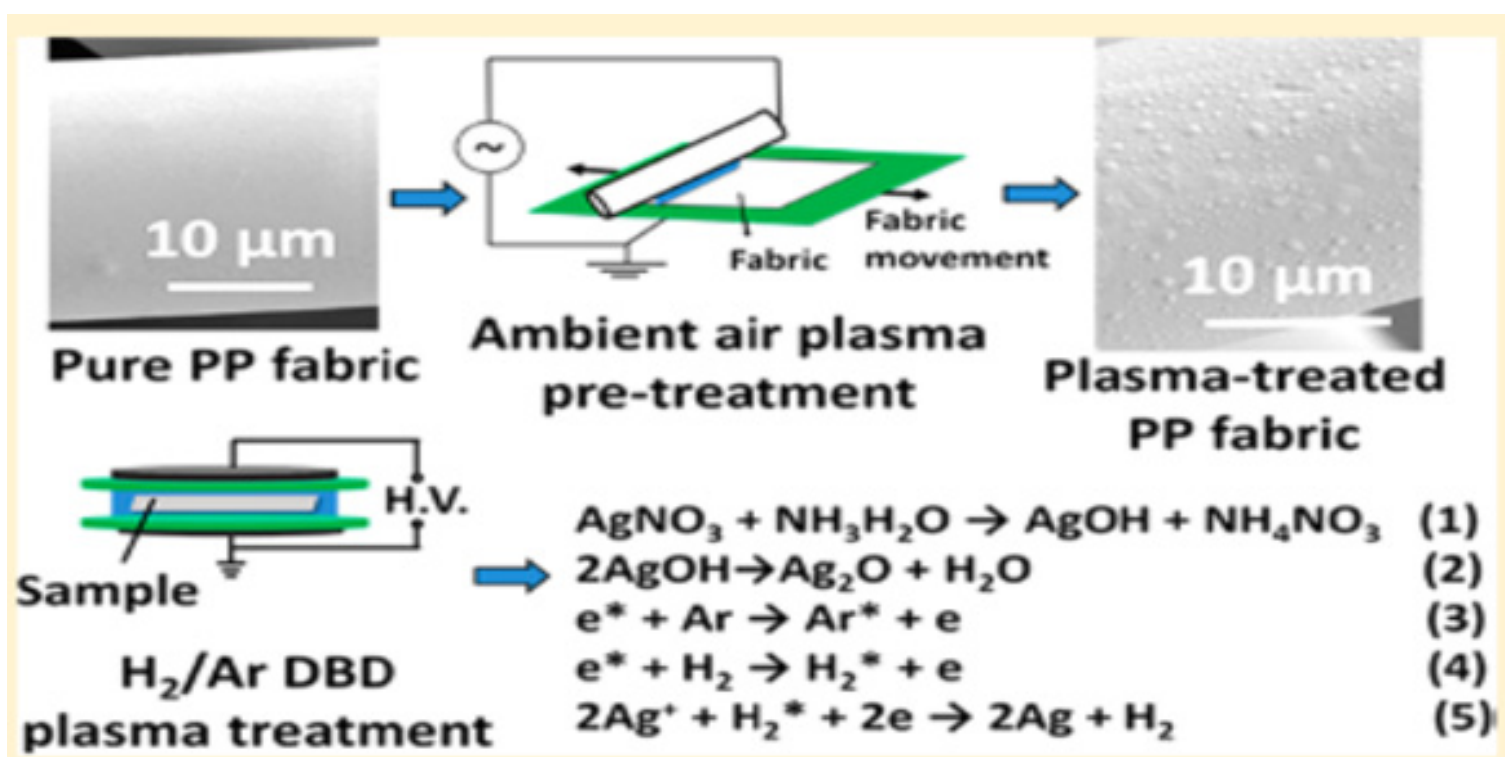

Fig. 18. Dielectric barrier discharge plasma coating nano silver 90.

Self-cleaning and UV protection properties of polyester fiber were improved dramatically after adjusting fiber with oxygen plasma and loaded with $\mathrm{TiO}_{2}$ by sol gel method ${ }^{91}$. Cellulosic fabric also indicated self-cleaning functionality after plasma and RF processing $\mathrm{TiO}_{2}{ }^{92} \cdot \mathrm{TiO}_{2}$ deposition on textile materials is also used for a biomedical application to improve the efficiency of antimicrobial textiles ${ }^{93}$. Utilizing radiofrequency oxygen plasma at the top of the input energy led to increasing fiber roughness as well as the adhesion of $\mathrm{TiO}_{2}$ on the treated fabric.

The antimicrobial textiles are used for medical, military, sports, leisure and bending. Its efficiency will increase by increasing the surface layer of silver nanoparticles on titanium dioxide which increases the amount of particles per unit area compared with the employment of an equal part of pure silver ${ }^{94},{ }^{95}$. Nanotechnology analysis in textiles, used numerous types of silver compounds, like silver nano-particles, silver chloride $(\mathrm{Ag} \mathrm{Cl})$, composite of silver and titanium dioxide $\left(\mathrm{Ag}-\mathrm{TiO}_{2}\right){ }^{85},{ }^{96},{ }^{97},{ }^{86}$.

There are various methods for coating of silver nano-particles on synthetic and natural textiles substrates. Sol-gel and dip coating are two examples for loading different textile fabrics with nano-particles ${ }^{86},{ }^{98}$. The exhaustion method is, also, another example for nano-particles deposition on fabric surface which leads to uniform distribution of nano-particles that is especially appropriate for simultaneous application of nano-particles and fabric dyeing. An effectively dyed material with antimicrobial activity is produced at the same time $^{85}$.

In addition to any or all the benefits of plasma treatment techniques, it permits the formation of polymers, nano-particals / plasma metal during this procedure freeze nanoparticles on the location, that is feasible throughout the deposition of plasma, that provides a coating method from the 1 st step cancels the requirement of dealing directly with the nano-particles [107], [108]. Moreover, by incorporating nano-particles within the compound close substance, it's potential to decrease the number of metal materials significantly compared to chemistry techniques and therefore have a major value impact, particularly once metals area unit precious, like silver or gold, area unit taken under consideration. this system permits the management of the quantity of metal materials that area unit integrated into the paint through the changes in particle size.

Microscopic methods for surface characterization of textiles in nanoscale

Scanning Electron Microscope (SEM)

Microscopic investigates are required in nanotechnology. Microscopic electron is taken into consideration one of the foremost common analysis tools that use the interaction of radiation emission of electrons with atoms of the sample to provide the exaggerated image. There are many kinds of electronic microscopes (SEM \& TEM) in step with the sort of electrons to produce the image. electron microscopes are exactitude instruments that play a extremely important role inside the nano-scale 
systems. It ought to be used for microscopy imaging inside the structure and composition of the nanoparticles and confirm measurements of physical properties and even the event and process of nanoscale structures [109], [110].

The SEM examinations of surface of sample by the beam of electrons so, the resulting photo contains a three-dimensional look is additionally appropriate in examining the structure of surface [111],[112],[113]. It provides the chance of direct observation of the surface morophology of textile nanocoatings and compared between untreated and nanocoated materials.[114].

\section{Transmission Electron Microscope (TEM)}

TEM is a very important technology within the textiles employed in a large range of applications. it's the power to produce detailed information about the ultrastructure and also the examination of the interior structure ${ }^{99}$. TEM information provides about plans to particles, and the structure of the basic shell of the particle, the crystalline nature of 99127 , and the thickness of the film, particle shape, and fiber diameter nanoparticles, and the distribution of nanoparticles through fiber nanoparticles and structure of the coating. In many types of literature, it has been investigated in the form of nano-materials, distribution and size fractions using pictures TEM ${ }^{100}$.

\section{Scanning Probe Microscopy (SPM):}

SPM is a kind of microscopic examination the surface of matter by using physical probe of matter. And also used for show the characterize topography of surface and roughness of substance, which is consider one of the key factors to determine hyper surfaces ${ }^{101}$.

AFM is category of the SPMs that are continuously used to confirm the observations result by SEM and TEM [118], [119, 132]. AFM is a lot of a good tool to research the nanostructure of matter with high-resolution impressive image. it has been accustomed show the three-dimensional structure, nonporous, surface texture, nanocluster, and diameters of materials [120]. AFM provides access to the surface texture and should provide pictures of substance in a very non-vacuum system and additionally works in gas or liquid phase and so, it does not would like any previous coating of samples comparison with SEM.

\section{$X$-ray powder diffraction $X R D$}

X-ray powder diffraction (XRD) may be a quick and simple technique that's mainly used for identifying the crystalline materials (e.g. minerals, inorganic compounds) and might also provide information on building block dimensions. The analyzed material under investigation should be finely ground, homogenized, and average bulk composition. ${ }^{102}$.

$\mathrm{X}$-ray diffraction is predicated on constructive interference of monochromatic X-rays and a crystalline sample. These X-rays are generated by a beam tube, filtered to provide monochromatic radiation, collimated to concentrate, and directed toward the sample. Besides; the XRD are often employed in other applications like measuring the children purity of the sample, identifying both the crystalline materials and samples' thin films characterizations. It can also identifies the finely grained minerals as clays and a mixture of their layers which cannot be easily determined optically.

\section{Future trends First}

The field of antimicrobial textiles- using plasma technology- shows a great development up to date. Although these fabrics offer a remarkable improvement in durability but still need more deep studies on aging effects. Therefore the continuity for more studies in this line is a crucial to merchandise (sell) this technique. The rational future development must create a full integration between plasma and antimicrobial end treatment units to understand bulk production. One main demand for this future development is reducing the experimentation time through associate degree accurately study mapping the characteristics of plasma particles with the strategy parameters. It would conjointly cause the event of applied math procedure strategies, that may open new avenues to theoretical studies throughout this field ${ }^{103}$.

\section{Second}

Functional textiles with multiple properties area unit the long run of the world textile and industry that giving new challenges and opportunities. These textiles can have numerous applications and the major one are within the field of practical wear wherever the buyer is exigent additional and additional comfort, easy-care, health \& hygiene. For additional consumers' satisfaction, they are expecting exploitation clothing- at an equivalent time- has protection against mechanical, thermal, chemical \& biological attacks. Among with the new functionalities, alternative fascinating properties of finishes embody the looks, feel \& sturdiness to washing. The sole thanks to meet of 
these expectations is developing new, advanced $\&$ innovative technologies for finishing of textile merchandise. the longer term in textile finishing analysis is actually supported in taking of various sciences as technology, biotechnology physics $\&$ biology. By the continuity of advances and development in these areas- with no doubt- will increase the production of smart intelligent and interactive textiles for the future ${ }^{104}$.

Third

Non-thermal plasma technology proved a great leap in enhancing the interaction of polymeric material. Deeper basic information of plasma technology can furthermore develop analysis to attain higher management over the incorporation of assorted purposeful cracks, cell adhesion, proliferation, and differentiation. Another necessary accomplishment that ought to be complete is dominant the changed surface (thickness, chemical composition) further developing new no thermal plasma sources, like small plasmas that, definitely, can produce new prospects and push the boundaries of current surface-control. Since new plasma sources square measure perpetually being developed, it should become attainable to change polymers at air pressure in associate degree industrial scope. Plasma- support surface modification is usually performed on two-dimensional chemical compound substrates. Within the future, there will be an excellent promotion during this field analysis and therefore the no inheritable experience is going to be additional useful once applying plasma-assisted surface modification techniques to $3 \mathrm{D}$ porous supports. Some preliminary studies have already incontestable the relevancy of plasma technology for the surface modification of the inside of porous scaffolds, however, within the close to future, it is expected that this analysis topic can become additional and additional necessary and there will be an excellent progression. At an equivalent time, new scaffold production techniques are going to be developed and powerfully believe is anticipated in rising the success of each biosensor and bio devices as a result of the mixture of extremely porous, one hundred interconnected scaffolds with progressive plasma surface modification technology ${ }^{105}$.

\section{References}

1. Jaison, J., Ahmed, B., Yen, S.C. et al.. Review on nanoparticles and nanostructured materials: history, sources, toxicity and regulations. Beilstein J Nanotechnol., 9, 1050-1074, (2018) .

2. Bhushan, B., Handbook of Nanotechnology., $2^{\text {th }}$ ed., Springer, (2007) .

J. Text. Color. Polym. Sci. Vol. 18, No. 1 (2021)
3. Ner, Y., Asemota, C., Olson, J. et al. Nanofiber Alignment on a Flexible Substrate

Nano Applied Material and interfaces., 1, 2093-2097, (2009) .

4. El Shafei, A., Shaarawy, S. \& Hebeish, A., Application of reactive cyclodextrin poly butyl acrylate preformed polymers containing nano$\mathrm{ZnO}$ to cotton fabrics and their impact on fabric performance. Carbohydra Polym. 79, 852-857, (2010).

5. Yetisen, K., Qu, H., Manbachi, A. et al.. Nanotechnol. Text. ACS Nano 10, 3042-3068.

6. El-Rafie MH, Mohamed AA, Shaheen ThI et al., (2010). Antimicrobial effect of silver nanoparticles produced by fungal process on cotton fabrics. Carbohydrate Polymers. 80, 779-782, (2016).

7. Sharma P, Udeniyan A, Mishra PK et al., International Journal of Scientific Research 4, 216-218, (2015).

8. Bickel, M. \& Som, C., nano textiles - Grundlagen und Leitprinzipien zur effizienten Entwicklung nachhaltiger Nanotextilien. www.empa.ch/plugin/ template/empa/*/113719. (2011).

9. Gesamtverband, nanotextil - Fragen und Antworten rund um die Nutzung von Nanotechnologien am Beispiel der deutschen Textilwirtschaft. http://www. textil-mode.de/data/nanobroschuere/ebroschuere. html. (2011).

10. Guadalupe, V. A. , Introductory Chapter: A Brief Semblance of the Sol-Gel Method in Research. use. (2018).

11. Kathirvelu, S., D’Souza, L. \& Dhurai, B., Multifunctional Formaldehyde Free Finishing of Cotton by Using Metal Oxide Nanoparticles and Ecofriendly Cross-Linkers. Indian J Fiber Text Res. 34, 267-273. (2019).

12. Keshmiri M, T. T., Mohseni M ., J Hazard Mater 128, 130-137. (2006).

13. Mahltig, B. \& Textor, T., Nanosols and textiles. . World Scientific Publishing;. (2008).

14. Brinker CJ \& G, S., Sol-Gel Science. 1989 Academic Press, New York:. (1989).

15. Wan Norfazilah \& Ismail, W., Sol-gel technology for innovative fabric finishing-A Review. $J$ Sol-Gel Sci Technol. (23 Marsh 2016).

16. Sakka, S., Handbook of Sol-Gel Sci.\& Techno. Springer. (2004). 
17. Nalwa, H. S., Handbook of organic-inorganic hybrid materials and nanocomposites. American Scientific Publisher, California, (2003).

18. Socrates, G., Infrared and Raman characteristic group frequencies. Wiley, New York, (2001).

19. Chen LF, Cai ZH, Zhang L et al., J.Mater Sci. 42, 1004-1009, (2007). .

20. He J, Zhou L, Soucek MD et al. , J Appl Polym Sci 105, 2376-2386, (2007).

21. Azizinejad F, Talu M, Abdouss M et al., Iran Polym $J$ 1433-38, (2005).

22. Costamagna V, Wunderlin D, Larranaga M et al., $J$ Appl Polym Sci 102, 2254-2263, (2006).

23. Violeta, P., Valentin, R., Anca, D. et al., Antireflective coating based on $\mathrm{TiO}_{2}$ nanoparticles modified with coupling agents via acid-catalyzed sol-gel method. Appl. Surf. Sci. 487, 819-824, (2019).

24. Yang, H., Zhu, S. \& Pan, N., J Appl Polym Sci 92, 3201-3210, (2004).

25. Ismai, W. N. W. , Sol-gel technology for innovative fabric finishing-A Review. J Sol-Gel Sci Technol., (23 March 2016).

26. S, V. \& S, K. , Mater Sci Eng 49, 1-4, (2013).

27. Berendjchi A, Khajavi R, Y. M., Nanoscale Res Lett 6, 594-601. (2011).

28. Zhang Q, Zhang W, Huang J et al., Mater Des 85, 796-799, (2015).

29. Costa AL, Ortelli S, Blosi M et al., Chem Eng J 225, 880-886, (2013).

30. Ibhadon AO \& P, F., Catalysts 3189-218. (2013).

31. Ibrahima, A., Eida, B. M., Abd El-Azizb, E. T. et al., Functionalization of linen/cotton pigment prints using inorganic nano structure materials. Carbohydr. Polym. 97 537- 545. (2013).

32. Ibrahima, N. A., Abou Elmaatyb, T. M., Eida, B. M. et al., Combined antimicrobial finishing and pigment printing of cotton/polyester blends. Carbohydr Polym 95, 379-388. (2013).

33. Liu, J. Y., Cheng, K. B. \& Hwang, J. F., Study on the electrical and surface properties of polyester, polypropylene, and polyamide 6 using pen-type RF plasma treatment. J. Ind. Text. 41, 123-141. (2011).
34. Jiang, S., Xu, J. \& Chen, Z., Enhanced electroconductivity and multi-shielding performance with copper,stainless steel and titanium coating onto PVA impregnated cotton fabric. J. Mater. Sci. Mater. Electron. 29, 5624-5633, (2018).

35. Vaideki, K., Jayakumar, S. \& Rajendran, R., Investigation on the effect of RF air plasma and neemleaf extract treatment on the surface modification and antimicrobial activity of cotton fabric. Appl. Surf. Sci. 254, 2472-2478, (2008).

36. Xue, C. H., Wang, R. L. \& Zhang, J., Growth of $\mathrm{ZnO}$ nanorod forests and characterization of $\mathrm{ZnO}$ coated nylonfibers. . Mater. Lett. 64, 327-330, (2010)

37. Yip, J., Jiang, S. \& Wong, C., Characterization of metallic textiles deposited by magnetron sputtering and traditional metallic treatments. Surf. Coat. Techno. 204, 380-385 (2009).

38. Linss, V., Challenges in the industrial deposition of transparent conductive oxide materials by reactive magnetron sputtering from rotatable targets. Thin Solid Films 634, 149-154, (2017).

39. Dhineshbabu, N. R. \& Bercy, E. W., Multifunctional property of graphene oxide nanostructures on silicacoated cotton fabrics. . J. Nanosci. Nanotechnol. 18, 4923, (2018).

40. Nam, Y. W., Kumar, S. \& Akhil, V., Multifunctional aramid/epoxy composite for stealth space hypervelocity impact shielding system. Compos. Struct. 193, 113-120, (2018).

41. Xiaohong, Y., Wei , Y., Huizhen, K. et al., Properties and application of multi-functional and structurally colored textile prepared by magnetron sputtering. $J$. Ind. Tex. 0, 1-17, (2020).

42. Miao, D., Jiang, S. \& Liu, J., Fabrication of copper and titanium coated textiles for sunlight management. J. Mater. Sci. Mater. Electron. 28, 9852-9858, (2017).

43. Ladam, G., Schaaf, P., Cuisinier, F. et al., Protein adsorption onto auto-assembled polyelectrolyte films. Langmuir 17, 878-882, (2001).

44. Hyde, K., Dong, H. \& Hinestroza, J. P., Effect of surface cationization on the conformal deposition of polyelectrolytes over cotton fibers. CELLULOSE 14, 615-623, (2007).

J. Text. Color. Polym. Sci. Vol. 18, No. 1 (2021) 
45. Decher, G. \& Schlenoff, J., Multilayer Thin Films. Wiley-VCH Verlag GmbH \& Co. KGaA, (2002).

46. Rahman, M., Tajabadi, F., Shooshtari, L. et al., Nanoparticulate Hollow TiO2 Fibers as Light Scatterers in Dye-Sensitized Solar Cells: Layer-byLayer Self-Assembly Parameters and Mechanism. Chem. Phys.Chem. 12, 966-973, (2011).

47. Ugur, S., Sarusık, M., Aktas, A. et al. , Modifying of Cotton Fabric Surface with Nano-ZnO Multilayer Films by Layer-by-Layer Deposition Method. Nanosca. Reseach. Lette. 5, 1204-1210, (2010).

48. Ugur, S., Sarusık, M. \& Aktas, A., Nano-Al2O3 multilayer film deposition on cotton fabrics by layer-by-layer deposition method. Materia. Res. Bull. 461202-1206, (2011).

49. Ugur, S. S., Sarusık, M. \& Aktas, A. H., NanoTiO2 Based Multilayer Film Deposition on Cotton Fabrics for UV-Protection. J. Fib. Polym. 12, 190196, (2011).

50. Dubas, S., Chutchawalkulchai, E., Egkasit, S. et al., Deposition of polyelectrolyte multilayers to improve the color fastness of silk. . Text. Res. J. 77, 427-441, (2007).

51. Dastjerdi, R., Montazer, M. \& Shahsavan, S., Anovel technique for producing durable multifunctiona textiles using nanocomposite coating. Collo. Surf. B: Biointerfaces. 81, 32-41, (2010).

52. Yadav, A., Prasad, V., Kathe, A. et al., Functional finishing in cotton fabrics using zinc oxide nanoparticles. Bull. Mater. Sci. 29, 641-645, (2006).

53. El-Molla, M. M., Eman, M. E. \& Mahmoud, E., Nanotechnology to improve coloration and antimicrobial properties of silk fabrics. Ind. J. Fib. Text. Res. 36, 266-271, (2011).

54. Montazer, M., Alimohammadi, F. S., Shamei, A. et al., In situ synthesis of nano silver on cotton using Tollens' reagent. Carbohydr. Polym. 87, 17061712, (2012).

55. Alimohammadi, F. S., Parvinzadeh, G. M. \& Shamei, A. A., novel method for coating of carbon nanotube on cellulose fiber using 1,2,3,4-butanetetracarboxylic acid as a cross-linking agent. Progre. in Organic Coat. doi:10.1016/j. porgcoat, 1-12, (2012).

J. Text. Color. Polym. Sci. Vol. 18, No. 1 (2021)
56. Parvinzadeh Gashti M, Alimohammadi F \& Shamei A., Preparation of water-repellent cellulose fibers using a polycarboxylic acid/hydrophobic silica nanocomposite coating. Surf. Coat. Technol. 206, 3208-3215, (2012).

57. Montazer, M., Shamei, A. \& Alimohammadi, F. S., tabilized nanosilver loaded nylon knitted fabric using BTCA without yellowing. Prog. Org. Coat. 74, 270-276, (2012).

58. El-Rafie, M., Mohamed, A., Shaheen, T. et al., Antimicrobial effect of silver nanoparticles produced by fungal process on cotton fabrics. Carbohydr Polym. 80, 779-782, (2010).

59. Maricel, A., Nicanor, C., Silviu, G. et al., Investigations of Transient Plasma Generated by Laser Ablation of Hydroxyapatite during the Pulsed Laser Deposition Process. Symm. 12, 1-15, (2020).

60. Morent, R., Geyter, N. D., Verschuren, J. et al., Non-thermal plasma treatment of textiles. Surf. Coat. Technol 14, 3427-3449, (2008).

61. Freidberg, H. \& Jeffrey, P., Plasma Physics and Fusion Energy. Cambridge University Press. (2008).

62. Virendra, K., Jerome, P., Hubert, R. et al. , Fluorocarbon Coatings Via Plasma Enhanced Chemical Vapor Deposition of $1 \mathrm{H}, 1 \mathrm{H}, 2 \mathrm{H}, 2 \mathrm{H}$ perfluorodecyl Acrylate 2,Morphology, Wettability and Antifouling Characterization ,. plasma process and polym 7, 926-938, (2010).

63. Klaus, D. W., Juergen, F. K., Marcin, H. et al., The future for plasma science and technology. Plasma Process Polym, 16, 1-29, (2019).

64. S.D., F. \& Sorin, M., Macromolecular plasmachemistry: an emerging field of polymer science. Progr. in Polymer Sci. 29, 815-885, (2004).

65. Hemen Dave, Lalita Ledwani† \& Nema S.K. , Nonthermal plasma: A promising green technology to improve environmental performance of textile industries. The Impact and Prospects of Green Chemistry for Textile Technology 199-249, (2019).

66. Chinta, S. K., Landage, S. M. \& Sathish, K. M., Plasma Technology \& Its Application In Textile Wet Processing IJERT., 1. (2012). 
67. Bahman, Z., Magnetic Confinement Fusion Driven Thermonuclear Energy, First Edition edn. Springer Publishing Company, University of New Mexico., (2017).

68. Deshmukh, R. R. \& Bhat, N. V., Pretreatments of Textiles Prior to Dyeing: Plasma Processing. In book: Text. Dyeing., ( 2011).

69. Jacobs, T., Declercq, H., Geyter, N. D. et al., Plasma surface modification of polylactic acid to promote interaction with fibroblasts,. J Mater Sci Technol 24, 469-478, (2013).

70. Joshi, A. S., Sharma, U., Bais, S. et al., Application of Plasma finishing on Cotton Fabric,. Int. Journal of Eng. Res. App. 5, 1-10, (2015).

71. Fridman A., "Plasma chemistry" Cambridge University Press. (2008).

72. Constantine, C., Johnson, D., Pearton, S. et al., Plasma etching of III-V semiconductors in $\mathrm{CH} 4 / \mathrm{H}$ 2/Ar electron cyclotron resonance discharges,. $J$. Vacuum Sci. Technol 8, 596-606, (1990).

73. Fracassi, F., d'Agostino, R., Lamendola, R. et al. , Plasma assisted dry etching of cobalt silicide for microelectronics applications,. J. Electrochem. Soc. 143, 701-707, (1996).

74. Lee, J., Hong, J. \& Pearton, S. K., Etching of InP at $>1 \mu \mathrm{m} / \mathrm{min}$ in $\mathrm{Cl} 2 / \mathrm{Ar}$ plasma chemistries,. $A P P L$ PHYS LETT 68, 847-849, (1996).

75. Chang, J. P., Arnold, J. C., Zau, G. C. et al., Kinetic study of low energy argon ion-enhanced plasma etching of polysilicon with atomic/molecular chlorin Plasma Modified Textiles for Biomedical Applications. J. Vacuum Sci. Techno. A: Vacuum, Surfaces, and Films 15, 1853-1863, (1997).

76. Washburn, N. R., Yamada, K. M., Simon, C. G. et al., Highthroughput investigation of osteoblast response to polymer crystallinity: influence of nanometer-scale roughness on proliferation,. Biomaterials 25, 1215-1224, (2004).

77. Khorasani, M. T., Mirzadeh, H. \& Irani, S., Plasma surface modification of poly (1-lactic acid) and poly (lactic-co-glycolic acid) films for improvement of nerve cells adhesion,. Radiat. Phys. Chem. 77, 280287, (2008).

78. Persin, Z., Mozetic, M., Vesel, A. et al., Plasma Induced Hydrophilic. Cellulose Wound Dressing, (2013).
79. Pieter, C., Rino, M. \& Nathalie, D. G., Plasma Mod. Text.Biomedi. Appl. the European Research Council under the European Union's Seventh Framework Program (FP/2007-2013),

80. Priya, M., Maryam, M., Ahmed, E. et al., Functional Military Textile: Plasma-Induced Graft Polymerization of DADMAC for Antimicrobial Treatment on Nylon-Cotton Blend Fabric. Plasma Chem. Plasma Process. 32, 833-843, (2012).

81. El-zeer, D. M., EL-Halwagy, A. A., EL-Kashouty, M. A. et al., Polymerization of Polyacrylonitrile Fabric by Using Atmospheric Pressure Glow Discharge Plasma and Its Printing Behavior. JER 4, 756-769, (2014).

82. Toh, H. S., Faure, R. L., Mohd, A. L. et al., A lightassisted in situ embedment of silver nanoparticles to prepare functionalized fabrics. Dov. Medical Press 10, 147-162, (2017).

83. Tomšič B., Simončič B., Orel B. et al., Antimicrobial Activity of $\mathrm{AgCl}$ Embedded in a Silica Matrix on Cotton Fabric. Carbohydr Polym 75, 618-626, (2009)

84. Jiang, S. X., Qin W, F. \& Zhang, L., Surface Functionalization of Nanostructured Silver- Coated Polyester Fabric by Magnetron Sputtering. Surf. Coat. Technol. 204, 3662-3667, (2010).

85. Gorensek, M., Gorjanc, M., Bukosek, V. et al., Functionalization of PET Fabrics by Corona and Nano Silver. Text .Res. J. 80, 253-262, (2010).

86. Marija, G., Marija, G., Petar, J. et al., Multifunctional Textiles - Modification by Plasma, Dyeing and Nanoparticles. licensee InTech., supported by Slovenian Research Agency, (2013).

87. Pedrosa P., Chappe J.-M., Fonseca C. et al., plasm Surface Modification of Polycarbonate and Poly(propylene) Substrates for Biomedical Electrodes. Plasma Process. Polym. 7, 676-686, (2010).

88. Zanini, S. \& Citterio, A. e. a., Applied Surface Science 427, 90-96., (2018).

89. Gorjanc, M. \& Gorenšek, M. e. a., Eco-Friendly Textile Dyeing and Finishing., (2013).

90. Peimei, D., Xiaoxiao, N.,Zhi, J.et al., Dual Dielectric Barrier Discharge Plasma Treatments for Synthesis of $\mathrm{Ag}-\mathrm{TiO} 2$ Functionalized Polypropylene Fabrics. Ind. Eng. Chem. Res. 7734-774158, (2019).

J. Text. Color. Polym. Sci. Vol. 18, No. 1 (2021) 
91. Borcia, C. \& Dumitrascu, N., Adhesion Properties of Polyamide-6 Fibres Treated by Dielectric Barrier Discharge. Surf. Coat. Technol 201, 1117-1123, (2006).

92. Qi, K., Xin, J. H., Daoud, W. A. et al., Functionalizing Polyester Fiber with a Selfcleaning Property using Anatase $\mathrm{TiO}_{2}$ and Low-Temperature Plasma Treatment. Int. J. Appl. Ceram. Technol. 4, 554-563, (2007).

93. Mejia, M. I., Marin, J. M., Restrepo, G. et al. , Selfcleaning Modified $\mathrm{TiO}_{2}$-cotton Pretreated by UVClight (185 nm) and RF-plasma in Vacuum and also under Atmospheric Pressure. Appl. Catal. b envi. 91, 481-488, (2009).

94. Rimai, D. S., Quesnel, D. J. \& Busnaina, A. A., The Adhesion of Dry Particles in the Nanometer to Micrometer-size Range. colloids surf. physicochemical.eng.aspects 165, 3-10, (2000).

95. Dastjerdi, R., Mojtahedi, M. R. M. \& Shoshtari, A. M., Investigating the Effect of Various Blend Ratios of Prepared Masterbatch Containing Ag/ $\mathrm{TiO}_{2}$ Nanocomposite on the Properties of Bioactive Continuous Filament Yarns. Fib. \& Polym. 9, 727-734. (2008).

96. Gavriliu, S., Lungu, M., Enescu, E. et al., Composite Nanopowder for Antibacterial Textiles. IND TEXTILA 61, 86-90, (2010).

97. Choi, O., Deng, K., Kim, N. et al., The Inhibitory Effects of Silver Nanoparticles, Silver Ions and Silver Chloride Colloids on Microbial Growth. Water Res. J. 42, 3066-3074, (2008).

98. Moazami, A., Montazer, M., Rashidi, A. et al., Antibacterial Properties of Raw and Degummed Silk with Nanosilver in Various Conditions. " $J$. Appl. Polym.sci. 118, 253-258, (2010).

99. Pana, Y., Hana, G., Mao, Z. et al., Structural characteristics and physical properties of lotus fibers obtained from Nelumbo nucifera petioles. . Carbohydr. Polym. 85, 188-195, (2011).

100.Pant, H. R., Bajgai, M. P., Nam, K. T. et al., Electrospun nylon-6 spider-net like nanofiber mat containing $\mathrm{TiO}_{2}$ nanoparticles: A multifunctional nanocomposite textile material. J. Hazard. Mater. 185, 124-130, (2011).
101. Bae GY, Min BG, Jeong YG et al., Superhydrophobicity of cotton fabrics treated with silica nanoparticles and water-repellent agent. $J$ COLLOID INTERF SCI 337, 170-175, (2009).

102. Visakh, P. M., Gordana, M. \& Daniel, P., Recent Developments in Polymer Macro, Micro and Nano Blends. Woodhead Publishing (2017).

103. Gang, S., Antimicrobial Textiles. Woodhead Publishing Series in Textiles. (2016).

104. Roshan, S., The Global Textile and Clothing Industry: Technological Advances and Future. Elsevier - Woodhead Publishing Series in Textiles,(2012).

105. Hemen, D., Lalita, L. \& Nema, S. K., Nonthermal plasma: A promising green technology to improve environmental performance of textile industries. Elsevier BV Woodhead Publishing. (2019). 


\section{تقنية النانو القائمة على البلازما لطلاء المنسوجات}

هند محمد أحمد و عزة الحلوجي قسم الصباغة و الطباعة و المساعدين ـ قسم بحوث الحمب النسيج ـ المركز القومي للبحوث ـ القاهرة ـ مصر.

تعرض هذه المر اجعة أهمية تقنية النانو كأداة جديدة في طباعة المنسوجات لإدخال خصائص متعددة الوظائف.

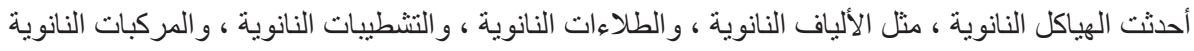

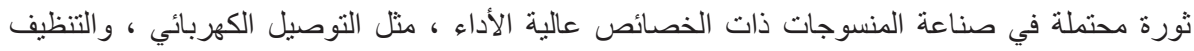

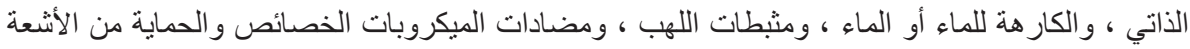

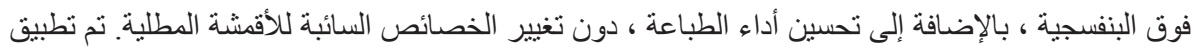

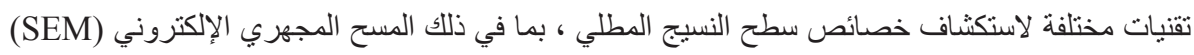

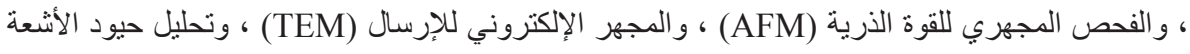

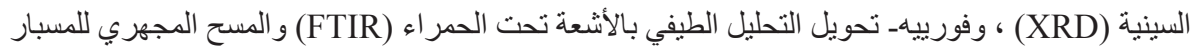

.(SPM) 